\title{
Review Article \\ Testing for HER2 in Breast Cancer: A Continuing Evolution
}

\author{
Sejal Shah and Beiyun Chen \\ Department of Laboratory Medicine and Pathology, Mayo Clinic, Rochester, MN 55905, USA \\ Correspondence should be addressed to Sejal Shah, shah.sejal@mayo.edu \\ Received 15 September 2010; Accepted 22 October 2010 \\ Academic Editor: Rohit Bhargava
}

Copyright () 2011 S. Shah and B. Chen. This is an open access article distributed under the Creative Commons Attribution License, which permits unrestricted use, distribution, and reproduction in any medium, provided the original work is properly cited.

\begin{abstract}
Human epidermal growth factor receptor 2 (HER2) is an important prognostic and predictive factor in breast cancer. HER2 is overexpressed in approximately 15\%-20\% of invasive breast carcinomas and is associated with earlier recurrence, shortened disease free survival, and poor prognosis. Trastuzumab (Herceptin) a "humanized" monoclonal antibody targets the extracellular domain of HER2 and is widely used in the management of HER2 positive breast cancers. Accurate assessment of HER2 is thus critical in the management of breast cancer. The aim of this paper is to present a comprehensive review of HER2 with reference to its discovery and biology, clinical significance, prognostic value, targeted therapy, current and new testing modalities, and the interpretation guidelines and pitfalls.
\end{abstract}

\section{Introduction and HER2 Biology}

In 1981, Shih et al. discovered novel transmissible genes which caused transformation of NIH 3T3 cells upon transfection of DNA obtained from rat neuroblastomas [1]. Subsequently, the same group identified a 185,000 Dalton phosphoprotein obtained from the sera of young mice injected with secondary transfectants containing neuroblastoma transforming sequence [2]. This neu oncogene was later identified in genomes of fetal rat neuro/glioblastomas cell lines derived from tumors induced by ethylnitrosurea [3]. The nucleic acid sequence of the neu gene was homologous to the erb-B oncogene and the neu-associated tumor antigen p-185 was antigenically related but distinct from the epidermal growth factor (EGF) receptor. Two other groups by screening the human genomic library using v-erbB as screening probes independently isolated similar erb-B related genes HER2 [4] and c-erbB-2 [5]. Upon further analysis, neu, HER2, and c-erbB-2 were identified as identical genes mapping on the same chromosome location [4, 6]. In 1985, the amplification of this gene in DNA prepared from tissue of human mammary carcinoma was first demonstrated by King et al. [7].

HER2 is a member of the epidermal growth factor (EGF) receptor family which consists of four members:
EGFR (HER1, erbB1), HER2 (erbB2), HER3 (erbB3), and HER4 (erbB4). The HER2 gene is located on chromosome $17 \mathrm{q} 12$ and encodes a $185-\mathrm{kDa}$ protein product which is a transmembrane receptor protein with tyrosine kinase activity [8-10]. The receptor is structurally composed of an extracellular ligand-binding domain, transmembrane domain, and an intracellular tyrosine kinase catalytic domain. Upon activation by a ligand, the receptors dimerize and undergo transphosphorylation to activate various intracellular signaling pathways which mediate cell proliferation and differentiation $[11,12]$. The cellular mechanism of HER2 activation is not completely understood, and there is no known stimulatory ligand for HER2 receptor homodimers. The HER2 receptor can, however, dimerize with other members of the EGFR family to form heterodimers, and these heterodimers involving HER2 have been shown to be more potent and stable [13]. In addition, crystal structures of rat HER2 have revealed a constitutively activated extracellular domain in the absence of a ligand [14].

Soon after its discovery, several in vivo and in vitro studies highlighted the oncogenic potential of HER2. Overexpression of HER2 was shown to be associated with cellular transformation and tumorogenesis in NIH 3T3 cells and human mammary epithelial cells [15-17]. In transgenic 
mice, overexpression of HER2 led to development of mammary tumors and induction of metastatic disease [18-20].

\section{Prognostic Value of HER2}

The prognostic value of HER2 amplification in human breast cancers was first determined by Slamon et al. in 1987 [21]. They evaluated tissues from 189 primary breast cancers and determined the role of HER2 as an independent prognostic factor. HER2 amplification was also shown to be a predictor of overall survival and time to relapse [21]. Currently, there are at least 107 published studies involving 39,730 patients that have discussed the prognostic significance of HER2 gene amplification (as assessed by southern blot, slot blot, polymerase chain reaction [PCR], fluorescent in situ hybridization [FISH] and chromogenic in situ hybridization [CISH]), and protein overexpression (as analyzed by western blot, immunohistochemistry [IHC], and enzyme-linked immunosorbent assay [ELISA]) [22]. Of these, 95 (88\%) studies showed HER2 gene amplification or protein overexpression in breast cancer as an important predictive factor by either univariate or multivariate analysis. Multivariate analysis was performed on 93 studies of which $68(73 \%)$ showed HER2 as an independent adverse prognostic factor. However, in $13(12 \%)$ studies there was no correlation between prognosis and HER2 status [22].

In node-positive patients, HER2 amplification or protein overexpression has been shown to be a poor predictor of clinical outcome [21, 23-35]. A recent study by Gilcrease et al. has shown that any degree of HER2 overexpression $(1+, 2+$ or $3+)$ was associated with increased tumor recurrence and decreased patient survival in a node-positive cohort of breast cancer patients $(n=91)$ treated with doxorubicin-based chemotherapy without trastuzumab [36]. A different study showed a distinct, intermediate outcome in patients with low-level HER2 amplification by FISH, with a ratio of 1.5-2.2, compared to HER2 unamplified tumors and tumors with HER2 ratios greater than 2.2 [37].

The predictive value of HER2 in node negative patients has been contentious. While some studies verify the adverse predictive value in node negative patients $[24,32,35$, 38-47], others have found no significant correlation with clinical outcome $[23,25,29-31,48-51]$. The differences in these study conclusions may be attributed to a multitude of factors including differences in the number of patients, patient population including those receiving systemic adjuvant therapy, length of followup, and most importantly HER2 status determination and interpretation techniques.

\section{Predictive Value of HER2}

In addition to the prognostic significance in breast cancer, HER2 amplification and protein expression has been shown to predict and modulate response of conventional chemotherapeutic agents.
3.1. Combination Chemotherapy. Conflicting studies have been reported regarding the benefit of combination chemotherapy with cyclophosphamide, methotrexate, and fluorouracil (CMF) in HER2-positive tumors. Some studies have shown decreased responsiveness of HER2-positive tumors to CMF therapy. Gusterson et al. reported a randomized study involving 1,506 breast cancer patients enrolled in the international (Ludwig) breast cancer study group trial $\mathrm{V}$ [30]. The patients were divided into subgroups of lymph-node positive $(n=746)$ and lymphnode negative $(n=740)$ patients. The patients in the node-positive group were given prolonged chemotherapy or a single cycle of perioperative chemotherapy (PeCT), and patients in the node-negative group were given single cycle of PeCT or no chemotherapy. They concluded that for node-positive patients, the effect of prolonged CMF chemotherapy, and for node-negative patients, the effect of PeCT on disease-free survival, was greater in HER2negative tumors when compared to HER2-positive tumors defined as focal or diffuse membrane positivity by IHC [30]. Similar results were shown in a subgroup of breast cancer patients $(n=179)$ with low-risk lesions without significant in situ component [43]. In this subgroup, the HER2-positive tumors (focal or diffuse membrane staining by IHC) showed significant decrease in disease-free survival at 5 years $(40 \%$ versus $80 \% ; P<.0001)$ and overall survival $(P=.0001)$ compared to HER2 negative tumors [43].

In contrast to these observations, a controlled clinical trial involving 386 node positive breast cancer patients with a 20-year followup who received 12 monthly cycles of adjuvant CMF $(n=207)$ or no further treatment after radical mastectomy $(n=179)$ showed that both HER2-positive (intermediate or strong membrane staining by IHC) and HER2-negative tumors benefited from treatment which was assessed by relapse-free survival and cause specific survival compared to the untreated patients [52]. These findings were confirmed by other large randomized study which had a median followup of 28.5 years [53].

3.2. Anthracycline-Based Chemotherapy. Though some studies have indicated that patients with locally advanced HER2 overexpressing breast cancers receiving prolonged or high-dose anthracycline-based chemotherapy show no significant change in survival [54], treatment failure [55], and development of distant metastasis [56] when compared to HER2-negative patients, most studies show benefit of anthracycline-based chemotherapy in HER2-positive tumors. Of 1572 patients with lymph node-positive early breast cancer enrolled in Cancer and Leukemia Group B (CALGB) trial randomized to receive high, moderate, and low doses of cyclophosphamide, doxorubicin, and fluorouracil, 442 random tumor samples were obtained and assessed for HER2 expression by IHC [57]. The results indicated that patients with high HER2 expression $(\geq 50 \%)$ who received high-dose chemotherapy had a significantly longer disease-free survival and overall survival as compared to the patients with no or low HER2 expression $(<50 \%)$ 
[57]. Similar observations of improved response to highdose anthracycline-based chemotherapy in HER2 amplified lymph node-positive breast cancers have also been shown by other studies $[58,59]$.

This was further confirmed in a recent large randomized study involving tissues from 710 premenopausal women with axillary lymph node-positive breast cancer where amplification of HER2 (HER2 to chromosome 17 ratio of $\geq 2$ ) was associated with clinical responsiveness to anthracycline containing chemotherapy containing cyclophosphamide, epirubicin and fluorouracil (CEF) when assessed for relapsefree survival and overall survival compared to patients receiving CMF or tumors that lacked amplification of HER2 [60]. Anthracyclines are topoisomerase inhibitors, and the response to these agents in HER2-positive tumors is postulated to be due to coamplification of topoisomerase II $\alpha$ (topo2a) gene which is located close to the HER2 gene on chromosome 17 [61-63]. Studies have shown that amplification of topo2a occurs exclusively in presence of HER2 amplification and that in the majority of tumors, topo2a amplification correlates with topo2a overexpression [64].

3.3. Tamoxifen. Approximately $75 \%$ of all invasive breast carcinomas are positive for estrogen receptors (ER) or progesterone receptors (PR) [65]. Even though HER2positive tumors show a significantly decreased expression of ER or PR in comparison to HER2-negative tumors, a substantial proportion still express ER or PR [66]. Patients with advanced breast cancer expressing hormone receptors (HR) show increased $(70 \%-80 \%)$ response to Tamoxifen therapy, though overall up to $50 \%$ of HR-positive tumors will not benefit, and approximately $10 \%$ of HR-negative tumors will respond to treatment [67]. Experimental and clinical evidence particularly in advanced-stage cancer have suggested an association between HER2 overexpression and resistance to endocrine therapies in general [68-73]. In a recent prospective study of 516 consecutive stage III patients, clinical outcome after 5-10 years following tamoxifen-based adjuvant therapy was compared between HR-positive/HER2-positive subgroup $(n=51)$ and HRpositive/HER2-negative subgroup $(n=129)$ [74]. Cases were considered HER2-positive if membrane staining in $>1 \%$ was identified in tumor cells. The study concluded that the disease-free survival and overall survival in patients receiving Tamoxifen alone or after chemotherapy was significantly lower in HR+/HER2+ group when compared to HR+/HER2 - group [74]. In another retrospective study, node-negative breast cancer patients randomly assigned to 2year adjuvant Tamoxifen or no further therapy were analyzed for HER2 protein overexpression by IHC [75]. After a median followup of 12 years, univariate analysis showed that adjuvant Tamoxifen significantly prolonged disease-free survival and overall survival in HER2-negative cases whereas it had no effect in HER2-positive cases (membrane staining in $>10 \%$ cells) [75].

In contrast to the above, a randomized controlled trial of 282 patients with ER positive tumors treated with adjuvant oophorectomy and Tamoxifen were evaluated for HER2 protein expression [76]. Univariate analysis showed risk reduction for all treated patients in both HER2-positive $(n=$ 73 ) and HER2-negative subgroups $(n=209)$ with a greater benefit in the HER2-positive group [76]. In another study by Berry et al., HER2 status in 651 ER-positive, node-positive patients was evaluated by three different methods (IHC, FISH, and PCR), and clinical outcome was evaluated after Tamoxifen therapy [77]. They concluded that the diseasefree survival and overall survival in the patients receiving Tamoxifen was not influenced by the HER2 status of the tumors [77].

3.4. Taxanes. Paclitaxol (Taxol), one the first taxanes examined in clinical trials has been shown to be effective against many cancers considered refractory to conventional chemotherapy. Paclitaxol exerts its cytotoxic effect by inhibiting microtubule disassembly and promoting tubulin polymerization, thus disrupting cell division [78]. Though in vitro studies have demonstrated resistance to taxanes in transfected mammary cells overexpressing HER2 [79, 80], in vivo studies have shown contradictory results. Baselga et al. studied the sensitivity of taxanes in women with metastatic breast cancer [81]. The response rate for taxanes was significantly greater in HER2-positive tumors (65\%) versus HER2-negative tumors (36\%). This sensitivity remained even after controlling for confounding variables which correlated with HER2 overexpression [81]. Similar benefits from paclitaxel containing regimens have also been shown by other studies in patients with HER2 gene amplification or protein overexpression and metastatic breast cancer [82, 83]. Contrasting to these observations, a randomized study involving 474 women showed that the response rate and overall survival were not related to HER2 status, and there was a trend towards shorter median time to treatment failure among women with HER2-positive tumors [84].

\section{HER2-Targeted Therapy}

4.1. Discovery of Trastuzumab. The high incidence of HER2 gene amplification and protein expression in breast cancer and its prognostic and predictive value make HER2 an attractive target for development of therapeutic agents. In 1985, soon after the discovery of HER2, a monoclonal anti-p185 antibody was shown to revert neu-transformed NIH 3T3 cells into a nontransformed phenotype [85]. Monoclonal antibodies targeting the extracellular domain of HER2 were subsequently developed by several laboratories [86-88]. Several other in vitro studies have confirmed the antineoplastic properties of monoclonal antibodies directed against HER2 expressing tumor cells demonstrated by inhibition of anchorage-dependent growth $[89,90]$, monolayer tumor growth [91], and colonies in soft agar [91-93] or by sensitizing the HER2 overexpressing cells to tumor necrosis factor alpha [92]. In addition, in vivo studies of monoclonal antibodies directed against HER2 have also shown to inhibit tumor cell growth in transgenic mice $[90,93]$. 
The use of these murine antibodies, however, is limited clinically due to the development of neutralizing human antibodies upon long-term use. To circumvent this dilemma, one of the most potent growth inhibitory anti-p185HER2, designated muMAb4D5 was humanized by gene conversion mutagenesis [91, 94]. This fusion gene (rhuMAb HER2) combined murine antigen-binding loops and human variable region framework residues and IgG1 constant domains. The product trastuzumab (Herceptin), a humanized monoclonal antibody specifically targeting the extracellular domain of the HER2 receptor, was launched in 1998 after approval by the US Food and Drug Administration (FDA). There are several proposed mechanisms of trastuzumab action including inhibition of HER2 shedding, inhibition of PI3K-AKT pathway, inhibition of cyclin E/cdk2 complex activity, attenuation of cell signaling, antibody-dependent cellular cytotoxicity, and inhibition of tumor angiogenesis $[95,96]$.

4.2. Efficacy and Safety of Trastuzumab. Following preclinical testing, the first clinical evidence of anti-HER2 targeted therapy was provided by phase II trials reported by Baselga et al. [97]. The study was performed in 46 patients with metastatic breast cancer with HER2 protein overexpression with at least $25 \%$ of tumor cells exhibiting membrane staining as measured by IHC. All patients were given singleagent therapy with trastuzumab. The overall response rate (complete and partial remission) in assessable patients $(n=$ 43) was $11.6 \%$. Additionally, $37 \%$ of the patients achieved minimal responses or stable disease. These results were confirmed by larger multinational clinical trial involving 222 women with HER2-positive metastatic breast carcinoma that had progressed after chemotherapy. After treatment with trastuzumab monotherapy, the overall response rate was 15\% (8 complete and 26 partial responses) with a median duration of response of 9.1 months [98]. In another study by Vogel et al., trastuzumab was given as first-line treatment in 114 randomized HER2-positive breast cancer patients with metastatic disease [99]. The overall response rate in this group was $26 \%$. More significantly, the response rate in tumors with $3+$ staining by IHC (strong complete membrane staining in $>10 \%$ tumor cells) was $35 \%$ compared to absence of response in tumors with $2+$ staining (weak to moderate complete membrane staining in $>10 \%$ tumor cells). The response rate in tumors with HER2 gene amplification by FISH was $34 \%$ compared to $7 \%$ in tumors that were negative by FISH [99].

Phase III trials were reported by Slamon et al., where 469 women with progressive metastatic HER2 positive breast cancers were randomly assigned into two groups [100]. The first group $(n=234)$ received standard chemotherapy alone, and the second group $(n=235)$ received standard chemotherapy plus trastuzumab. Patients who received chemotherapy with trastuzumab showed longer time to disease progression (median, 7.4 versus 4.6 months), higher rate of response (50\% versus 32\%), longer duration of response (median, 9.1 versus 6.1 months), lower rate of death at 1 year (22\% versus $33 \%)$, longer survival (median, 25.1 versus 20.3 months), and a 20 percent decrease in risk of death [100]. Favorable clinical outcome was also noted when trastuzumab combined with Paclitaxel was administered after doxorubicin and cyclophosphamide to patients enrolled in National Surgical Adjuvant Breast and Bowel Project (NSABP) B-31 and the North Central Cancer Treatment Group (NCCTG) N9831 trials with surgically removed HER2-positive breast cancers [101]. Similar results have been reported by other phase III trials evaluating response of HER2-positive breast cancers treated with neoadjuvant chemotherapy and trastuzumab [102104].

During the clinical trials of trastuzumab, it was observed that a small proportion of patients developed cardiotoxicity manifested as congestive heart failure, cardiomyopathy, and/or decrease in ejection fraction [98]. Occurrence of these unexpected adverse events prompted a retrospective review of all patients enrolled in seven phase II and III trials. The analysis revealed increased risk of developing cardiac dysfunction in patients receiving trastuzumab [105]. The severity was observed to be greatest in patients receiving trastuzumab with anthracycline and cyclophosphamide (27\%), compared to those receiving trastuzumab and paclitaxel $(13 \%)$ or trastuzumab alone $(3 \%-7 \%)$. It was also noted that though the cardiac dysfunction was symptomatic in most patients $(75 \%)$, standard treatment for congestive heart failure led to improvement in most patients (79\%). Overall, it was concluded that in spite of these adverse effects treatment was justified in patients with metastatic breast cancer due to the improved overall survival following therapy [105].

4.3. Newer HER2-Targeting Drugs. Lapatinib (Tykerb) is a novel reversible dual inhibitor of HER2 and EGFR tyrosine kinases [106, 107]. The antitumorogenic properties of this drug was examined in human normal and tumor-derived cell lines by in vivo and in vitro studies [108] and in patients with advanced malignancies [109]. Lapatinib was approved by the FDA in 2007 for use in previously treated advanced metastatic breast cancers which overexpressed HER2 in combination with Capecitabine [110]. In a randomized phase III clinical trial, 324 women with previously treated locally advanced or metastatic HER2-positive breast cancer were assigned to receive Lapatinib with Capecitabine or Capecitabine alone [111]. The patients with combination therapy had 49 (30\%) disease progression events compared to $72(45 \%)$ events with monotherapy. Additionally, the median time to progression was 8.4 months for patients receiving combination therapy compared to 4.4 months in patients receiving monotherapy [111]. In a similar phase III trial of 399 women, addition of Lapatinib showed prolongation of time to progression and a trend towards improved overall survival [112].

Other HER2-targeting agents which are still being developed and are in preclinical testing stages include Pertuzumab (Omnitarg), which binds HER2 and sterically hinders the recruitment of HER2 into heterodimers [113], and Ertumaxomab, a bispecific antibody targeting HER2 and CD3 [114]. 
Targeted therapy with MDX-H210 [115] and 2B1 [116] have shown limited response in initial clinical trials.

\subsection{ASCO Update of HER2 as Marker for Breast Cancer}

The American Society of Clinical Oncology (ASCO) published an update of recommendations for use of HER2 as a marker for breast cancer [117]. According to these updated guidelines, HER2 should be evaluated in every primary invasive breast cancer either at the time of diagnosis or at recurrence in order to guide selection of trastuzumab for treatment. Recommendations were also made regarding utility of HER2 to predict response to specific chemotherapeutic agents. It was suggested that if chemotherapy was considered in a patient with HER2-positive breast cancer, an anthracycline should be considered. For trastuzumab-based therapy, it was suggested that a nonanthracycline regimen may produce similar outcome. The benefit of taxane-based chemotherapy was considered controversial, and use of HER2 to guide its use was not recommended.

\section{HER2 Testing}

The importance of HER2 as a prognostic, predictive, and therapeutic marker in invasive breast cancer is well recognized, and therefore, it is critical to validate and standardize testing techniques in order to make an accurate assessment of HER2 status. The significant contradictions in various studies can at least in part be attributed to differences in HER2 testing and interpretation [118-121]. Techniques which have been used to assess HER2 protein overexpression are immunohistochemistry, ELISA analysis of tumor cytosols or serum, and Western blot, and methods used to evaluate HER2 gene amplification include Southern blot, slot blot, CISH, FISH, and PCR [22].

Use of solid matrix blotting techniques like Southern blot, slot blot, and especially Western blot are significantly limited due to the dilutional artifacts in the tumor sample. In breast cancer specimens, these artifacts may be composed of benign breast ductal cells, acini, stromal cells, inflammatory cells, and vascular structures resulting in false negative cases [120-122]. Additionally, false positive results may be obtained due to inclusion of in situ carcinoma which can express high levels of HER2 [123-126]. In addition, these techniques need a large amount of tissues which would not be available in biopsy specimens. PCR is a sensitive technique; however, it is also affected by dilutional artifacts, and the analysis is time consuming and labor intensive [120]. The absence of simultaneous morphological assessment in the above studies is also a significant disadvantage.

Contrary to the above, analysis by IHC and FISH can be automated and allow the simultaneous assessment of tumor morphology while eliminating difficulties with dilution artifacts.

6.1. HER2 Immunohistochemistry. IHC analysis of HER2 is a simple-to-perform, widely available and inexpensive test. It is nevertheless affected by several variables including tissue-fixation methods, reagents, assay protocols, antibody sensitivities and specificities, and scoring systems [118, 127129]. In general, testing of freshly frozen tissues is more reliable than paraffin-embedded tissues as formaldehyde causes cross linking of proteins hindering the access of antibody to the epitope $[118,122,130]$. However, practically, it is not possible to have fresh tissues available in all cases especially when testing at reference laboratories and analyzing archival tissues.

The reagents and antibodies used in an assay are other critical factors. Antibodies differ in their sensitivity to detect HER2 epitopes. The important considerations in an assay are the type of antibody used, clonality of the antibody (monoclonal versus polyclonal), and the dilution factor used. Studies comparing different antibodies have shown marked variation in HER2 detection [118, 131, 132]. Press et al. conducted a study analyzing sensitivity and specificity of 7 polyclonal and 21 monoclonal anti-HER2 antibodies on paraffin-embedded tissues of 187 breast cancers with known HER2 protein overexpression and gene amplification analyzed by Northern blot, Western blot, IHC, and Southern blot performed on frozen tumor specimens [118]. The sensitivity of the antibodies ranged from $6 \%$ to $80 \%$ and none of the antibodies were able to detect all the cases of breast cancer with HER2 overexpression. In a recent study with the help of College of American Pathologists (CAP), HER2 proficiency was evaluated with use of HER2 peptide analyte controls. Of the 109 participants, who returned evaluable stained slides, suboptimal staining was identified in $20(18.3 \%)$ cases. The causes of failure in these cases were antigen retrieval errors (35\%), antibody or staining protocol problems (20\%), or a combination of both (45\%) [133].

Several studies have shown correlation between membrane-staining pattern of HER2 and protein overexpression [118]. Though cytoplasmic staining can be recognized in cases of breast cancer, it has not been shown to correlate with gene amplification [118], HER2 mRNA levels $[134,135]$, or have an association with poor prognosis in a subset of node-positive women [34]. One study, however, has shown an association between moderate to strong cytoplasmic staining of HER2 with poor prognosis [136]. Another limitation of IHC scoring system is interobserver variability, particularly in cases with moderate $(2+)$ membrane staining $[137,138]$.

The two FDA-approved IHC-based tests for testing HER2 overexpression are HercepTest (Dako, Carpinteria, CA) which uses A085 polyclonal antibody and Pathway (Ventana, Tucson, AZ) which uses 4B5 monoclonal antibody. The overall concordance between DAKO HercepTest and clinical trial assays (CTA) in 548 breast tumor specimens was $79 \%$ [139]. However, a $2+$ score by HercepTest did not correlate well with the CTA, where approximately $42 \%$ of cases with HercepTest $2+$ score were negative by CTA $(0-1+)$ [139]. The low specificity of HercepTest was also highlighted by other studies $[132,140]$. The Pathway kit was first introduced in 2002 when it used a monoclonal antibody CB11. This antibody was replaced by a new monoclonal antibody 4B5 in 2008, which showed sharper membrane 
staining and less background staining when compared to CB11 and a higher correlation with FISH with an excellent interlaboratory reproducibility when evaluated in a total of 322 breast cancer patients [141].

6.2. HER2 Fluorescent In Situ Hybridization. FISH is a more reliable, reproducible, sensitive, and accurate procedure which is less affected by tissue fixation and analytical variables compared to IHC. It also offers the benefit of simultaneous evaluation of morphology and gene amplification. Relative to solid matrix blotting procedures, analysis of HER2 gene amplification by FISH showed a sensitivity of $98 \%$ and specificity of $100 \%$ [142]. The technique, however, is more complex and labor intensive than IHC.

The FDA-approved FISH-based tests for HER2 amplification are PathVysion (Abbott Molecular, Des Plaines, IL), INFORM (Ventana, Tucson, AZ) and HER2 FISH pharmDx (Dako, Carpinteria, CA). The PathVysion HER2 probe kit is a dual color FISH (D-FISH) assay which uses probes targeting HER2 gene and chromosome 17 centromere. The HER2 gene amplification is calculated based on the ratio of HER2 gene copies per chromosome 17 copy number. On the other hand, the INFORM assay is a single-color FISH (S-FISH) assay with a HER2 probe alone. In this assay, the HER2 gene amplification is calculated as an absolute value of HER2 gene copy number per tumor nucleus.

Several studies have assessed the use of tissue microarrays as an efficient method to analyze HER2 gene amplification by FISH in a high-throughput manner [143-145].

6.3. Concordance between FISH and IHC. In general, there is concordance between tumors scored as $3+$ by IHC and FISH, while cases scored 2+ by IHC showed the most discrepancy [146-154]. Correlation studies in 2279 cases with invasive breast carcinoma showed a concordance of HER2 status between IHC and both D-FISH (87\%) and S-FISH (86\%) [155]. Specifically, excellent concordance was seen in groups scored $0,1+$, and $3+$ by IHC for both D-FISH (97\%) and S-FISH (96\%), while the most discordant category was the group scored 2+ [155].

In a multicenter study involving 426 women with breast carcinoma being considered for trastuzumab study, the correlation of IHC by HercepTest and FISH by PathVysion was analyzed [156]. It was found that only $2 / 270(0.7 \%)$ of IHC 0 or $1+$ cases were FISH positive and 6/102 (5.9\%) IHC $3+$ cases were FISH negative. Of the 54 cases with $2+$ staining, only $26(48 \%)$ showed HER2 gene amplification by FISH [156]. Several other studies have also shown absence of gene amplification in subset of cases which were scored $2+$ by IHC $[147,149,153,154,157,158]$. Hence, a combined approach with IHC and FISH analysis was recommended for accurate HER2 testing particularly for cases with moderate staining with IHC [137, 148, 149, 152, 157].

In a study evaluating clinical outcomes of 799 patients enrolled in 3 clinical trials with $2+$ and $3+$ scoring on IHC, it appeared that clinical benefit from trastuzumab therapy was restricted to patients with FISH positive (78\%) metastatic breast cancers with higher overall response rate and longer duration of survival when compared to FISH negative (22\%) patients [159]. Hence, they concluded that analysis by FISH is a preferred method to select patients for trastuzumab therapy [159]. Other studies have also suggested the use of FISH as a superior method which should be done as the first line of HER2 status assessment [160-162] or at least in all cases scored $2+$ or $3+$ by IHC $[163,164]$. In contrast to the above, an analysis of 2963 breast cancer specimens obtained from 135 hospitals and cancer centers showed that the FISH test had a significantly higher failure rate ( $5 \%$ versus $0.08 \%)$, reagent cost ( $\$ 140$ versus $\$ 10$ ), longer testing time (36 hours versus 4 hours), and interpretation time ( 7 minutes versus 45 seconds) in comparison to IHC testing [165]. It was concluded that HER2 status determination is most effective by using IHC as the methods of choice and performing FISH in cases with moderate (2+) staining [165].

\section{Current Issues with HER2 Testing}

Several studies have identified a subset of false positive breast cancers that are IHC $3+$ and negative by FISH ranging from $3 \%$ to $22 \%$ of all positive cases [146, 148, 153, 156-158, 160]. These inconsistencies may be due to several causes including variability in tissue fixation and processing, intratumoral heterogeneity, and polysomy of chromosome $17[166,167]$.

7.1. Effect of Polysomy 17 on HER2 Testing. Polysomy of chromosome 17 is frequent, and depending on the definition of polysomy, it may be seen in $20 \%-30 \%$ of invasive breast carcinomas [168-171]. Analysis of polysomy 17 requires the use of dual color FISH, and its presence can complicate accurate assessment of HER2 status [172]. Studies have shown polysomy 17 as a contributing factor in a small subset of tumors, which were IHC3 + but lacked HER2 gene amplification [166, 169, 171].

While some studies have shown an association between unamplified polysomy 17 tumors with IHC $3+$ protein expression and adverse prognostic features [173], these observations have not been validated by others $[170,174]$. A study by Hofman et al. reported a response to trastuzumab monotherapy in FISH-negative tumors with polysomy 17 [175]. However, in a recent study involving 405 patients with metastatic breast cancer, it was observed that polysomy 17 in absence of HER2 amplification did not predict the response to Lapatinib with Paclitaxol compared to paclitaxel alone [176].

A recent analysis of HER2 status by array comparative genomic hybridization in breast carcinoma samples $(n=97)$ has shown that polysomy 17 is a rare event and suggest that the cases detected by FISH represent amplification of chromosome 17 centromere rather than true polysomy [177].

7.2. Intratumoral Heterogeneity. Another pitfall in accurate HER2 status determination and discordance between FISH and IHC is the presence of intratumoral heterogeneity. Several studies have reported the presence of intratumoral heterogeneity of HER2 in breast cancers [178-181], which 
may reflect genetic divergence in the tumor cells during clonal evolution [182]. Intratumoral heterogeneity can also contribute to discordance in results between primary and asynchronous metastatic and recurrent tumors [180, 183], synchronous metastatic tumors [184] and small biopsy specimens $[180,181]$.

A study analyzing HER2 protein expression in patients with locally advanced breast cancers who received neoadjuvant chemotherapy $(n=39)$ and patients who did not receive chemotherapy $(n=60)$ reported that the HER2 IHC scores significantly reduced in patients who received therapy (28.5\%) compared to those who did not (11.7\%) [185]. In contrast, examination of HER2 amplification in needle core biopsies and subsequent excisions of 100 patients showed excellent concordance, even in a subset of patients who received neoadjuvant therapy, suggesting that heterogeneity is not a significant confounding factor when analyzing HER2 by FISH [186].

In 2008, the CAP/American College of Medical Genetics Cytogenetics resource committee panel defined and provided practice guidelines for breast tumors with genetic heterogeneity [187]. Genetic heterogeneity of HER2 is defined as presence of greater than $5 \%$ but less than $50 \%$ of infiltrating tumor cells with a HER2/CEP17 ratio of greater than 2.2 [187]. Currently, the clinical significance of genetic heterogeneity and possible benefit from anti-HER2 therapy is not known and additional clinical trials are required.

\section{Newer Modalities of HER2 Testing}

8.1. Chromogenic In Situ Hybridization. In 2008, FDAapproved SPOT-Light HER2 CISH assay (Invitrogen, Carlsbad, CA) which uses formalin-fixed paraffin-embedded sections and can be used to detect HER2 as a primary test or as a reflex test in IHC equivocal (2+) cases. Amplification by this method is defined as HER2 gene enumerated as greater than 5 dots, clusters (small or large), or a combination per nucleus in a majority $(>50 \%)$ of carcinoma cells [188]. This is further categorized into low and high amplification. Nonamplification is defined as $1-5$ dots of HER2 gene per nucleus present in a majority $(>50 \%)$ of carcinoma cells [188].

Tanner et al. first described the utility of CISH as an alternative to FISH [189]. A high concordance between FISH and CISH has been established by several other studies [190194]. In a recent study involving 226 consecutive cases of invasive breast carcinomas obtained from two institutions, tissues were evaluated for HER2 protein expression and amplification by IHC (HercepTest), FISH (PathVysion), and CISH (SPOT-Light) [195]. They compared the results between FISH and CISH using the manufacturer's criteria (nonamplified and amplified) and the ASCO/CAP criteria (nonamplified, equivocal, and amplified). The concordance between CISH and FISH for positive and negative results was $98.5 \%$ and $98.6 \%$ at the two institutions using the manufacturers' criteria and $99 \%$ and $99.1 \%$ using the ASCO/CAP criteria [195]. The advantages of CISH include ability to analyze the test by light microscopy, preservation of morphologic features, permanent signals which will not fade with slide storage, lower reagent costs, and need for less expertise than FISH $[193,196]$.

8.2. Metallographic In Situ Hybridization. Silver In Situ Hybridization (SISH) is an automated enzymatic metallographic ISH technique that is based upon deposition of silver at the target site following an enzymatic reaction. The signals are permanent and can be assessed by bright field microscopes. In a multi-institution study of 298 invasive breast carcinomas, concordance between HER2 gene amplification by SISH and FISH was $96.6 \%$ when analyzed by FDA approved criteria and $98.9 \%$ when analyzed by ASCO/CAP guidelines after excluding equivocal cases [197]. In addition, the study showed high interobserver reproducibility. Other studies have also shown SISH to be an accurate method to detect gene amplification in paraffin-embedded formalinfixed tissue $[198,199]$ and cytology preparations [200].

Other bright field metallographic techniques which have been studied for analyses of HER2 status include goldfacilitated in situ hybridization [201] and EnzMet GenePro which allows simultaneous detection of HER2 gene status by deposition of silver and protein expression [202].

8.3. Brightfield Double In Situ Hybridization. Brightfield Double In Situ Hybridization (BDISH) is a recently described automated technique which utilizes two probes targeting HER2 gene and chromosome 17 centromere (CEN 17) and allows simultaneous analysis of morphological features by a brightfield microscope [203]. Their analysis of 94 breast cancer cases demonstrated a high concordance between HER2 FISH and BDISH using the historical scoring method (98.9\%) and the ASCO/CAP criteria including the FISH equivocal cases (95.7\%) and after excluding the FISH equivocal cases (100\%) [203].

\section{Current ASCO/CAP Guidelines for HER2 Testing and Interpretation}

Accurate assessment of HER2 status is critical in management of patients with invasive breast cancer. In an attempt to standardize HER2 testing and to improve the accuracy and reproducibility of the test results, the American Society of Clinical Oncology/College of American Pathologists (ASCO/CAP) panel has made recommendations for HER2 interpretation and testing [204]. The panel recommended determination of HER2 status in all cases of invasive breast carcinoma. Algorithms for interpreting HER2 gene amplification by FISH and protein expression by IHC are provided. The guidelines by ASCO/CAP define an HER2 IHC staining of $3+$ as uniform intense membrane staining in $>30 \%$ of invasive tumor cells as compared to previously defined $>10 \%$ strong staining. Cases with weak to moderate complete membrane staining in at least $10 \%$ of cells are considered equivocal $(2+)$, and in these cases, HER2 gene amplification with fluorescent in situ hybridization (FISH) should be tested. For FISH, the tumor is negative for HER2 gene amplification if the ratio of 
HER2 gene signals to chromosome17 signals is $<1.8$ or HER2 gene copy number is $<4.0$, equivocal when the ratio is $1.8-2.2$ or HER2 gene copy number is $4.0-6.0$ and positive if the ratio is $>2.2$ or HER2 gene copy number is >6.0. Guidelines for tissue processing include keeping the time from tissue acquisition to fixation as short as possible and fixation in $10 \%$ neutral buffered formalin for 6-48 hours. Additional guidelines for optimal test validation, internal quality assurance procedures, external proficiency assessment, and laboratory accreditation are also provided.

9.1. Impact of New ASCO/CAP Guidelines. Studies analyzing the impact of the new ASCO/CAP guidelines have shown an improved concordance between IHC and FISH results, improved accuracy, and decrease in number of inconclusive FISH tests after raising the cutoff level to greater than $30 \%$ invasive tumor cells for HER2 3+ tumors [205207]. Other studies have additionally shown decrease in interobserver variability by application of the new criteria [208]. In another study, however, there was no change in concordance between FISH results and IHC3+ cases and all the 27 cases scored as $3+$ by IHC remained $3+$ after using the new threshold [209]. In our retrospective study, $12(8.5 \%)$ of 141 cases had $11 \%-30 \%$ of invasive tumor cells with intense membrane staining which would have their status changed from $3+$ to $2+$ (equivocal) based on the new guidelines [210]. The overall concordance between FISH and IHC was improved; however, up to $3 \%$ of patients would be disallowed from receiving anti-HER2 therapy based on the new guidelines. Thus, the important question remains whether improved concordance translates into better prediction of response to anti-HER2 therapy. This is also critical in light of recent data, which demonstrated benefit of trastuzumab in patients with HER2 overexpression (IHC 3+) regardless of whether there was evidence of gene amplification $[211,212]$. A retrospective analysis of 2268 patients from N9831 adjuvant trastuzumab phase III trial where enrollment was based on previous criteria of HER 2 IHC $>10 \%(3+)$ or FISH $\geq 2.0$ showed that a small percentage $(1.5 \%)$ of patients eligible for trastuzumab therapy under FDA-approved definitions would not be eligible by the new ASCO/CAP guidelines. Additionally, the trastuzumab effect appeared similar for HER2-positive patients regardless of ASCO/CAP or FDA-approved guidelines [213].

\section{Conclusions}

In conclusion, the confirmed clinical advantages of HER2targeted therapy in patients with HER2-positive disease necessitate that all patients continue to be tested for HER2 status on diagnosis [204, 211]. When conducting HER2 testing, we should be aware of various analytical and clinical factors that may affect the testing results and the clinical significance of false positive or negative results.

\section{References}

[1] C. Shih, L. C. Padhy, M. Murray, and R. A. Weinberg, "Transforming genes of carcinomas and neuroblastomas introduced into mouse fibroblasts," Nature, vol. 290, no. 5803, pp. 261-264, 1981.

[2] L. C. Padhy, C. Shih, D. Cowing, R. Finkelstein, and R. A. Weinberg, "Identification of a phosphoprotein specifically induced by the transforming DNA of rat neuroblastomas," Cell, vol. 28, no. 4, pp. 865-871, 1982.

[3] A. L. Schechter, D. F. Stern, L. Vaidyanathan et al., "The neu oncogene: an erb-B-related gene encoding a 185,000-M(r) tumour antigen," Nature, vol. 312, no. 5994, pp. 513-516, 1984.

[4] L. Coussens, T. L. Yang-Feng, and Y.-C. Liao, "Tyrosine kinase receptor with extensive homology to EGF receptor shares chromosomal location with neu oncogene," Science, vol. 230, no. 4730, pp. 1132-1139, 1985.

[5] K. Semba, N. Kamata, K. Toyoshima, and T. Yamamoto, "A v-erbB-related protooncogene, c-erbB-2, is distinct from the c-erbB-1/epidermal growth factor-receptor gene and is amplified in a human salivary gland adenocarcinoma," Proceedings of the National Academy of Sciences of the United States of America, vol. 82, no. 19, pp. 6497-6501, 1985.

[6] A. L. Schechter, M. C. Hung, L. Vaidyanathan et al., "The neu gene: an erbB-homologous gene distinct from and unlinked to the gene encoding the EGF receptor," Science, vol. 229, no. 4717, pp. 976-978, 1985.

[7] C. R. King, M. H. Kraus, S. A. Aaronson et al., "Amplification of a novel v-erbB-related gene in a human mammary carcinoma," Science, vol. 229, no. 4717, pp. 974-976, 1985.

[8] D. F. Stern, P. A. Heffernan, and R. A. Weinberg, "P185, a product of the neu proto-oncogene, is a receptorlike protein associated with tyrosine kinase activity," Molecular and Cellular Biology, vol. 6, no. 5, pp. 1729-1740, 1986.

[9] T. Akiyama, C. Sudo, H. Ogawara, K. Toyoshima, and T. Yamamoto, "The product of the human c-erbB-2 gene: a 185kilodalton glycoprotein with tyrosine kinase activity," Science, vol. 232, no. 4758, pp. 1644-1646, 1986.

[10] S. I. Fukushige, K. I. Matsubara, M. Yoshida et al., "Localization of a novel v-erbB-related gene, c-erbB-2, on human chromosome 17 and its amplification in a gastric cancer cell line," Molecular and Cellular Biology, vol. 6, no. 3, pp. 955-958, 1986.

[11] Y. Yarden and M. X. Sliwkowski, "Untangling the ErbB signalling network," Nature Reviews Molecular Cell Biology, vol. 2, no. 2, pp. 127-137, 2001.

[12] M. M. Moasser, "The oncogene HER2: its signaling and transforming functions and its role in human cancer pathogenesis," Oncogene, vol. 26, no. 45, pp. 6469-6487, 2007.

[13] D. Graus-Porta, R. R. Beerli, J. M. Daly, and N. E. Hynes, "ErbB-2, the preferred heterodimerization partner of all ErbB receptors, is a mediator of lateral signaling," EMBO Journal, vol. 16, no. 7, pp. 1647-1655, 1997.

[14] H.-S. Cho, K. Mason, K. X. Ramyar et al., "Structure of the extracellular region of HER2 alone and in complex with the Herceptin Fab," Nature, vol. 421, no. 6924, pp. 756-760, 2003.

[15] R. M. Hudziak, J. Schlessinger, and A. Ullrich, "Increased expression of the putative growth factor receptor p185HER2 causes transformation and tumorigenesis of NIH $3 \mathrm{~T} 3$ cells," Proceedings of the National Academy of Sciences of the United States of America, vol. 84, no. 20, pp. 7159-7163, 1987. 
[16] P. P. Di Fiore, J. H. Pierce, and M. H. Kraus, "erbB-2 is a potent oncogene when overexpressed in NIH/3T3 cells," Science, vol. 237, no. 4811, pp. 178-182, 1987.

[17] J. H. Pierce, P. Arnstein, E. DiMarco et al., "Oncogenic potential of erbB-2 in human mammary epithelial cells," Oncogene, vol. 6, no. 7, pp. 1189-1194, 1991.

[18] W. J. Muller, E. Sinn, P. K. Pattengale, R. Wallace, and P. Leder, "Single-step induction of mammary adenocarcinoma in transgenic mice bearing the activated c-neu oncogene," Cell, vol. 54, no. 1, pp. 105-115, 1988.

[19] L. Bouchard, L. Lamarre, P. J. Tremblay, and P. Jolicoeur, "Stochastic appearance of mammary tumors in transgenic mice carrying the MMTV/c-neu oncogene," Cell, vol. 57, no. 6, pp. 931-936, 1989.

[20] C. T. Guy, M. A. Webster, M. Schaller, T. J. Parsons, R. D. Cardiff, and W. J. Muller, "Expression of the neu protooncogene in the mammary epithelium of transgenic mice induces metastatic disease," Proceedings of the National Academy of Sciences of the United States of America, vol. 89, no. 22, pp. 10578-10582, 1992.

[21] D. J. Slamon, G. M. Clark, S. G. Wong, W. J. Levin, A. Ullrich, and W. L. McGuire, "Human breast cancer: correlation of relapse and survival with amplification of the HER-2/neu oncogene," Science, vol. 235, no. 4785, pp. 177-182, 1987.

[22] J. S. Ross, E. A. Slodkowska, W. F. Symmans, L. Pusztai, P. M. Ravdin, and G. N. Hortobagyi, "The HER-2 receptor and breast cancer: ten years of targeted anti-HER-2 therapy and personalized medicine," Oncologist, vol. 14, no. 4, pp. 320-368, 2009.

[23] A. K. Tandon, G. M. Clark, G. C. Chamness, A. Ullrich, and W. L. McGuire, "HER-2/neu oncogene protein and prognosis in breast cancer," Journal of Clinical Oncology, vol. 7, no. 8, pp. 1120-1128, 1989.

[24] S. Paik, R. Hazan, E. R. Fisher et al., "Pathologic findings from the National Surgical Adjuvant Breast and Bowel Project: prognostic significance of erbB-2 protein overexpression in primary breast cancer," Journal of Clinical Oncology, vol. 8, no. 1, pp. 103-112, 1990.

[25] A. Borg, A. K. Tandon, H. Sigurdsson et al., "HER-2/neu amplification predicts poor survival in node-positive breast cancer," Cancer Research, vol. 50, no. 14, pp. 4332-4337, 1990.

[26] R. Anbazhagan, R. D. Gelber, R. Bettelheim, A. Goldhirsch, and B. A. Gusterson, "Association of c-erbB-2 expression and S-phase fraction in the prognosis of node positive breast cancer," Annals of Oncology, vol. 2, no. 1, pp. 47-53, 1991.

[27] C. Lovekin, I. O. Ellis, A. Locker et al., "c-erbB-2 oncoprotein expression in primary and advanced breast cancer," British Journal of Cancer, vol. 63, no. 3, pp. 439-443, 1991.

[28] F. Rilke, M. I. Colnaghi, N. Cascinelli et al., "Prognostic significance of HER-2/NEU expression in breast cancer and its relationship to other prognostic factors," International Journal of Cancer, vol. 49, no. 1, pp. 44-49, 1991.

[29] S. M. O’Reilly, D. M. Barnes, R. S. Camplejohn, J. Bartkova, W. M. Gregory, and M. A. Richards, "The relationship between c-erbB-2 expression, S-phase fraction and prognosis in brest cancer," British Journal of Cancer, vol. 63, no. 3, pp. 444-446, 1991.

[30] B. A. Gusterson, R. D. Gelber, A. Goldhirsch et al., "Prognostic importance of c-erbB-2 expression in breast cancer," Journal of Clinical Oncology, vol. 10, no. 7, pp. 1049-1056, 1992.

[31] S. Toikkanen, H. Helin, J. Isola, and H. Joensuu, "Prognostic significance of HER-2 oncoprotein expression in breast cancer: a 30-year follow-up," Journal of Clinical Oncology, vol. 10, no. 7, pp. 1044-1048, 1992.

[32] R. Seshadri, F. A. Firgaira, D. J. Horsfall, K. McCaul, V. Setlur, and P. Kitchen, "Clinical significance of HER-2/neu oncogene amplification in primary breast cancer. the South Australian Breast Cancer Study Group," Journal of Clinical Oncology, vol. 11, no. 10, pp. 1936-1942, 1993.

[33] L. C. Hartmann, J. N. Ingle, L. E. Wold et al., "Prognostic value of c-erbB2 overexpression in axillary lymph node positive breast cancer: results from a randomized adjuvant treatment protocol," Cancer, vol. 74, no. 11, pp. 2956-2963, 1994.

[34] B. Têtu and J. Brisson, "Prognostic significance of HER-2/neu oncoprotein expression in node- positive breast cancer: the influence of the pattern of immunostaining and adjuvant therapy," Cancer, vol. 73, no. 9, pp. 2359-2365, 1994.

[35] N. Quénel, J. Wafflart, F. Bonichon et al., "The prognostic value of c-erbB2 in primary breast carcinomas: a study on 942 cases," Breast Cancer Research and Treatment, vol. 35, no. 3, pp. 283-291, 1995.

[36] M. Z. Gilcrease, W. A. Woodward, M. M. Nicolas et al., "Even low-level HER2 expression may be associated with worse outcome in node-positive breast cancer," American Journal of Surgical Pathology, vol. 33, no. 5, pp. 759-767, 2009.

[37] K. C. Jensen, D. A. Turbin, S. Leung et al., "New cutpoints to identify increased HER2 copy number: analysis of a large, population-based cohort with long-term follow-up," Breast Cancer Research and Treatment, vol. 112, no. 3, pp. 453-459, 2008.

[38] C. Wright, B. Angus, S. Nicholson et al., "Expression of cerbB-2 oncoprotein: a prognostic indicator in human breast cancer," Cancer Research, vol. 49, no. 8, pp. 2087-2090, 1989.

[39] J. Ro, A. El-Naggar, J. Y. Ro et al., "c-erbB-2 amplification in node-negative human breast cancer," Cancer Research, vol. 49, no. 24, pp. 6941-6944, 1989.

[40] J. Winstanley, T. Cooke, G. D. Murray et al., "The long term prognostic significance of c-erbB-2 in primary breast cancer," British Journal of Cancer, vol. 63, no. 3, pp. 447-450, 1991.

[41] R. Dykins, I. P. Corbett, J. A. Henry et al., "Long-term survival in breast cancer related to overexpression of the cerbB-2 oncoprotein: an immunohistochemical study using monoclonal antibody NCL-CB11," Journal of Pathology, vol. 163, no. 2, pp. 105-110, 1991.

[42] M. C. Paterson, K. D. Dietrich, J. Danyluk et al., "Correlation between c-erbB-2 amplification and risk of recurrent disease in node-negative breast cancer," Cancer Research, vol. 51, no. 2, pp. 556-567, 1991.

[43] D. C. Allred, G. M. Clark, A. K. Tandon et al., "HER2/neu in node-negative breast cancer: prognostic significance of overexpression influenced by the presence of in situ carcinoma," Journal of Clinical Oncology, vol. 10, no. 4, pp. 599-605, 1992.

[44] M. F. Press, M. C. Pike, V. R. Chazin et al., "Her-2/neu expression in node-negative breast cancer: direct tissue quantitation by computerized image analysis and association of overexpression with increased risk of recurrent disease," Cancer Research, vol. 53, no. 20, pp. 4960-4970, 1993.

[45] M. Giai, R. Roagna, R. Ponzone, M. De Bortoli, C. Dati, and P. Sismondi, "Prognostic and predictive relevance of c-erbB2 and ras expression in node positive and negative breast cancer," Anticancer Research, vol. 14, no. 3, pp. 1441-1450, 1994. 
[46] M. F. Press, L. Bernstein, P. A. Thomas et al., "HER$2 /$ neu gene amplification characterized by fluorescence in situ hybridization: poor prognosis in node-negative breast carcinomas," Journal of Clinical Oncology, vol. 15, no. 8, pp. 2894-2904, 1997.

[47] I. L. Andrulis, S. B. Bull, M. E. Blackstein et al., "Neu/erbB-2 amplification identifies a poor-prognosis group of women with node-negative breast cancer," Journal of Clinical Oncology, vol. 16, no. 4, pp. 1340-1349, 1998.

[48] A. Borg, B. Baldetorp, M. Fernö, D. Killander, H. Olsson, and H. Sigurdsson, "ERBB2 amplification in breast cancer with a high rate of proliferation," Oncogene, vol. 6, no. 1, pp. 137-143, 1991.

[49] J. C. Babiak, J. Hugh, and S. Poppema, "Significance of cerbB-2 amplification and DNA aneuploidy: analysis in 78 patients with node-negative breast cancer," Cancer, vol. 70, no. 4, pp. 770-776, 1992.

[50] P. P. Rosen, M. L. Lesser, C. D. Arroyo, M. Cranor, P. Borgen, and L. Norton, "Immunohistochemical detection of HER2/neu in patients with axillary lymph node negative breast carcinoma: a study of epidemiologic risk factors, histologic features, and prognosis," Cancer, vol. 75, no. 6, pp. 1320-1326, 1995.

[51] S.-S. Ko, Y.-S. Na, C.-S. Yoon et al., "The significance of c-erbB-2 overexpression and p53 expression in patients with axillary lymph node-negative breast cancer: a tissue microarray study," International Journal of Surgical Pathology, vol. 15, no. 2, pp. 98-109, 2007.

[52] S. Ménard, P. Valagussa, S. Pilotti et al., "Response to cyclophosphamide, methotrexate, and fluorouracil in lymph node-positive breast cancer according to HER2 overexpression and other tumor biologic variables," Journal of Clinical Oncology, vol. 19, no. 2, pp. 329-335, 2001.

[53] G. Bonadonna, A. Moliterni, M. Zambetti et al., "30 Years' follow up of randomised studies of adjuvant CMF in operable breast cancer: cohort study," British Medical Journal, vol. 330, no. 7485, pp. 217-220, 2005.

[54] B. Têtu, J. Brisson, V. Plante, and P. Bernard, "p53 and cerbB-2 as markers of resistance to adjuvant chemotherapy in breast cancer," Modern Pathology, vol. 11, no. 9, pp. 823-830, 1998.

[55] J. D. Bitran, B. Samuels, Y. Trujillo, L. Klein, L. Schroeder, and J. Martinec, "Her2/neu overexpression is associated with treatment failure in women with high-risk stage II and stage IIIA breast cancer (> 10 involved lymph nodes) treated with high-dose chemotherapy and autologous hematopoietic progenitor cell support following standard-dose adjuvant chemotherapy," Clinical Cancer Research, vol. 2, no. 9, pp. 1509-1513, 1996.

[56] L. M. Vargas-Roig, F. E. Gago, O. Tello, M. T. Martin De Civetta, and D. R. Ciocca, "c-erbB-2 (HER-2/neu) protein and drug resistance in breast cancer patients treated with induction chemotherapy," International Journal of Cancer, vol. 84, no. 2, pp. 129-134, 1999.

[57] H. B. Muss, A. D. Thor, D. A. Berry et al., "c-erbB-2 expression and response to adjuvant therapy in women with node- positive early breast cancer," The New England Journal of Medicine, vol. 330, no. 18, pp. 1260-1266, 1994.

[58] S. Paik, J. Bryant, C. Park et al., "erbB-2 and response to doxorubicin in patients with axillary lymph node- positive, hormone receptor-negative breast cancer," Journal of the National Cancer Institute, vol. 90, no. 18, pp. 1361-1370, 1998.
[59] A. D. Thor, D. A. Berry, D. R. Budman et al., "erbB-2, p53, and efficacy of adjuvant therapy in lymph node-positive breast cancer," Journal of the National Cancer Institute, vol. 90, no. 18, pp. 1346-1360, 1998.

[60] K. I. Pritchard, L. E. Shepherd, F. P. O'Malley et al., "HER2 and responsiveness of breast cancer to adjuvant chemotherapy," The New England Journal of Medicine, vol. 354, no. 20, pp. 2103-2111, 2006.

[61] K. Smith, S. Houlbrook, M. Greenall, J. Carmichael, and A. L. Harris, "Topoisomerase II $\alpha$ co-amplification with erbB2 in human primary breast cancer and breast cancer cell lines: relationship to m-AMSA and mitoxantrone sensitivity," Oncogene, vol. 8, no. 4, pp. 933-938, 1993.

[62] T. A. H. Järvinen, M. Tanner, V. Rantanen et al., "Amplification and deletion of topoisomerase II $\alpha$ associate with ErbB-2 amplification and affect sensitivity to topoisomerase II inhibitor doxorubicin in breast cancer," American Journal of Pathology, vol. 156, no. 3, pp. 839-847, 2000.

[63] A. Di Leo, D. Larsimont, D. Gancberg et al., "HER-2 and topo-isomerase II $\alpha$ as predictive markers in a population of node-positive breast cancer patients randomly treated with adjuvant CMF or epirubicin plus cyclophosphamide," Annals of Oncology, vol. 12, no. 8, pp. 1081-1089, 2001.

[64] R. Bhargava, P. Lal, and B. Chen, "HER-2/neu and topoisomerase II $\alpha$ gene amplification and protein expression in invasive breast carcinomas: chromogenic in situ hybridization and immunohistochemical analyses," American Journal of Clinical Pathology, vol. 123, no. 6, pp. 889-895, 2005.

[65] W. F. Anderson, N. Chatterjee, W. B. Ershler, and O. W. Brawley, "Estrogen receptor breast cancer phenotypes in the Surveillance, Epidemiology, and End Results database," Breast Cancer Research and Treatment, vol. 76, no. 1, pp. 2736, 2002.

[66] P. Lal, L. K. Tan, and B. Chen, "Correlation of HER-2 status with estrogen and progesterone receptors and histologic features in 3,655 invasive breast carcinomas," American Journal of Clinical Pathology, vol. 123, no. 4, pp. 541-546, 2005.

[67] I. C. Henderson, H. Mouridsen, O. Abe et al., "Effects of adjuvant tamoxifen and of cytotoxic therapy on mortality in early breast cancer. An overview of 61 randomized trials among 28,896 women," The New England Journal of Medicine, vol. 319, no. 26, pp. 1681-1692, 1988.

[68] C. C. Benz, G. K. Scott, J. C. Sarup et al., "Estrogendependent, tamoxifen-resistant tumorigenic growth of MC3F-7 cells transfected with HER2/neu," Breast Cancer Research and Treatment, vol. 24, no. 2, pp. 85-95, 1992.

[69] C. Wright, S. Nicholson, B. Angus et al., "Relationship between c-erbB-2 protein product expression and response to endocrine therapy in advanced breast cancer," British Journal of Cancer, vol. 65, no. 1, pp. 118-121, 1992.

[70] J. G. M. Klijn, E. M. J. J. Berns, M. Bontenbal, and J. Foekens, "Cell biological factors associated with the response of breast cancer to systemic treatment," Cancer Treatment Reviews, vol. 19, pp. 45-63, 1993.

[71] R. J. Pietras, J. Arboleda, D. M. Reese et al., "HER-2 tyrosine kinase pathway targets estrogen receptor and promotes hormone-independent growth in human breast cancer cells," Oncogene, vol. 10, no. 12, pp. 2435-2446, 1995.

[72] S. J. Houston, T. A. Plunkett, D. M. Barnes, P. Smith, R. D. Rubens, and D. W. Miles, "Overexpression of c-erbB2 is an independent marker of resistance to endocrine therapy in advanced breast cancer," British Journal of Cancer, vol. 79, no. 7-8, pp. 1220-1226, 1999. 
[73] G. Konecny, G. Pauletti, M. Pegram et al., "Quantitative association between HER-2/neu and steroid hormone receptors in hormone receptor-positive primary breast cancer," Journal of the National Cancer Institute, vol. 95, no. 2, pp. 142-153, 2003.

[74] F. E. Gago, M. A. Fanelli, and D. R. Ciocca, "Co-expression of steroid hormone receptors (estrogen receptor $\alpha$ and/or progesterone receptors) and Her2/neu (c-erbB-2) in breast cancer: clinical outcome following tamoxifen-based adjuvant therapy," Journal of Steroid Biochemistry and Molecular Biology, vol. 98, no. 1, pp. 36-40, 2006.

[75] C. Carlomagno, F. Perrone, C. Gallo et al., "c-erbB2 overexpression decreases the benefit of adjuvant tamoxifen in earlystage breast cancer without axillary lymph node metastases," Journal of Clinical Oncology, vol. 14, no. 10, pp. 2702-2708, 1996.

[76] R. R. Love, N. B. Duc, T. C. Havighurst et al., "HER2/neu overexpression and response to oophorectomy plus tamoxifen adjuvant therapy in estrogen receptor-positive premenopausal women with operable breast cancer," Journal of Clinical Oncology, vol. 21, no. 3, pp. 453-457, 2003.

[77] D. A. Berry, H. B. Muss, A. D. Thor et al., "HER-2/neu and p53 expression versus tamoxifen resistance in estrogen receptor-positive, node-positive breast cancer," Journal of Clinical Oncology, vol. 18, no. 20, pp. 3471-3479, 2000.

[78] E. K. Rowinsky and R. C. Donehower, "Drug therapy: paclitaxel (taxol)," The New England Journal of Medicine, vol. 332, no. 15, pp. 1004-1014, 1995.

[79] D. Yu, B. Liu, T. Jing et al., "Overexpression of both p185(cerbB2) and p170(mdr-1) renders breast cancer cells highly resistant to taxol," Oncogene, vol. 16, no. 16, pp. 2087-2094, 1998.

[80] F. Ciardiello, R. Caputo, G. Pomatico et al., "Resistance to taxanes is induced by c-erbB-2 overexpression in human MCF-10A mammary epithelial cells and is blocked by combined treatment with an antisense oligonucleotide targeting type I protein kinase A," International Journal of Cancer, vol. 85, no. 5, pp. 710-715, 2000.

[81] J. Baselga, A. D. Seidman, P. P. Rosen, and L. Norton, "HER2 overexpression and paclitaxel sensitivity in breast cancer: therapeutic implications," Oncology, vol. 11, no. 3, Supplement 2, pp. 43-48, 1997.

[82] G. E. Konecny, C. Thomssen, H. J. Lück et al., "HER-2/neu gene amplification and response to paclitaxel in patients with metastatic breast cancer," Journal of the National Cancer Institute, vol. 96, no. 15, pp. 1141-1151, 2004.

[83] D. F. Hayes, A. D. Thor, L. G. Dressler et al., "HER2 and response to paclitaxel in node-positive breast cancer," The New England Journal of Medicine, vol. 357, no. 15, pp. 1496-1506, 2007.

[84] L. N. Harris, G. Broadwater, N. U. Lin et al., "Molecular subtypes of breast cancer in relation to paclitaxel response and outcomes in women with metastatic disease: results from CALGB 9342," Breast Cancer Research, vol. 8, no. 6, article R66, 2006.

[85] J. A. Drebin, V. C. Link, and D. F. Stern, "Down-modulation of an oncogene protein product and reversion of the transformed phenotype by monoclonal antibodies," Cell, vol. 41, no. 3, pp. 697-706, 1985.

[86] B. M. Fendly, M. Winget, R. M. Hudziak, M. T. Lipari, M. A. Napier, and A. Ullrich, "Characterization of murine monoclonal antibodies reactive to either the human epidermal growth factor receptor or HER2/neu gene product," Cancer Research, vol. 50, no. 5, pp. 1550-1558, 1990.
[87] I.-M. Harwerth, W. Wels, B. M. Marte, and N. E. Hynes, "Monoclonal antibodies against the extracellular domain of the erbB-2 receptor function as partial ligand agonists," The Journal of Biological Chemistry, vol. 267, no. 21, pp. 15160-15167, 1992.

[88] J. W. Park, R. Stagg, G. D. Lewis et al., "Anti-p185HER2 monoclonal antibodies: biological properties and potential for immunotherapy," Cancer Treatment and Research, vol. 61, pp. 193-211, 1992.

[89] J. A. Drebin, V. C. Link, R. A. Weinberg, and M. I. Greene, "Inhibition of tumor growth by a monoclonal antibody reactive with an oncogene-encoded tumor antigen," Proceedings of the National Academy of Sciences of the United States of America, vol. 83, no. 23, pp. 9129-9133, 1986.

[90] I.-M. Harwerth, W. Wels, J. Schlegel, M. Müller, and N. E. Hynes, "Monoclonal antibodies directed to the erbB-2 receptor inhibit in vivo tumour cell growth," British Journal of Cancer, vol. 68, no. 6, pp. 1140-1145, 1993.

[91] G. D. Lewis, I. Figari, B. Fendly et al., "Differential responses of human tumor cell lines to anti-p185(HER2) monoclonal antibodies," Cancer Immunology Immunotherapy, vol. 37, no. 4, pp. 255-263, 1993.

[92] R. M. Hudziak, G. D. Lewis, M. Winget, B. M. Fendly, H. M. Shepard, and A. Ullrich, "p185(HER2) monoclonal antibody has antiproliferative effects in vitro and sensitizes human breast tumor cells to tumor necrosis factor," Molecular and Cellular Biology, vol. 9, no. 3, pp. 1165-1172, 1989.

[93] J. A. Drebin, V. C. Link, and M. I. Greene, "Monoclonal antibodies reactive with distinct domains of the neu oncogeneencoded p185 molecule exert synergistic anti-tumor effects in vivo," Oncogene, vol. 2, no. 3, pp. 273-277, 1988.

[94] P. Carter, L. Presta, C. M. Gorman et al., "Humanization of an anti-p185(HER2) antibody for human cancer therapy," Proceedings of the National Academy of Sciences of the United States of America, vol. 89, no. 10, pp. 4285-4289, 1992.

[95] G. Valabrega, F. Montemurro, and M. Aglietta, "Trastuzumab: mechanism of action, resistance and future perspectives in HER2-overexpressing breast cancer," Annals of Oncology, vol. 18, no. 6, pp. 977-984, 2007.

[96] K. P. Garnock-Jones, G. M. Keating, and L. J. Scott, "Trastuzumab: a review of its use as adjuvant treatment in human epidermal growth factor receptor 2 (HER2)-positive early breast cancer," Drugs, vol. 70, no. 2, pp. 215-239, 2010.

[97] J. Baselga, D. Tripathy, J. Mendelsohn et al., "Phase II study of weekly intravenous recombinant humanized anti-p185HER2 monoclonal antibody in patients with HER2/neu-overexpressing metastatic breast cancer," Journal of Clinical Oncology, vol. 14, no. 3, pp. 737-744, 1996.

[98] M. A. Cobleigh, C. L. Vogel, D. Tripathy et al., "Multinational study of the efficacy and safety of humanized antiHER2 monoclonal antibody in women who have HER2overexpressing metastatic breast cancer that has progressed after chemotherapy for metastatic disease," Journal of Clinical Oncology, vol. 17, no. 9, pp. 2639-2648, 1999.

[99] C. L. Vogel, M. A. Cobleigh, D. Tripathy et al., "Efficacy and safety of trastuzumab as a single agent in first-line treatment of HER2-overexpressing metastatic breast cancer," Journal of Clinical Oncology, vol. 20, no. 3, pp. 719-726, 2002.

[100] D. J. Slamon, B. Leyland-Jones, S. Shak et al., "Use of chemotherapy plus a monoclonal antibody against her2 for metastatic breast cancer that overexpresses HER2," The New England Journal of Medicine, vol. 344, no. 11, pp. 783-792, 2001. 
[101] E. H. Romond, E. A. Perez, J. Bryant et al., "Trastuzumab plus adjuvant chemotherapy for operable HER2-positive breast cancer," The New England Journal of Medicine, vol. 353, no. 16, pp. 1673-1684, 2005.

[102] A. U. Buzdar, V. Valero, N. K. Ibrahim et al., "Neoadjuvant therapy with paclitaxel followed by 5-fluorouracil, epirubicin, and cyclophosphamide chemotherapy and concurrent trastuzumab in human epidermal growth factor receptor 2-positive operable breast cancer: an update of the initial randomized study population and data of additional patients treated with the same regimen," Clinical Cancer Research, vol. 13, no. 1, pp. 228-233, 2007.

[103] F. Peintinger, A. U. Buzdar, H. M. Kuerer et al., "Hormone receptor status and pathologic response of HER2positive breast cancer treated with neoadjuvant chemotherapy and trastuzumab," Annals of Oncology, vol. 19, no. 12, pp. 2020-2025, 2008.

[104] L. Gianni, W. Eiermann, V. Semiglazov et al., "Neoadjuvant chemotherapy with trastuzumab followed by adjuvant trastuzumab versus neoadjuvant chemotherapy alone, in patients with HER2-positive locally advanced breast cancer (the NOAH trial): a randomised controlled superiority trial with a parallel HER2-negative cohort," The Lancet, vol. 375, no. 9712, pp. 377-384, 2010.

[105] A. Seidman, C. Hudis, K. M. Pierri et al., "Cardiac dysfunction in the trastuzumab clinical trials experience," Journal of Clinical Oncology, vol. 20, no. 5, pp. 1215-1221, 2002.

[106] D. W. Rusnak, K. Affleck, S. G. Cockerill et al., "The characterization of novel, dual ErbB-2/EGFR, tyrosine kinase inhibitors: potential therapy for cancer," Cancer Research, vol. 61, no. 19, pp. 7196-7203, 2001.

[107] W. Xia, R. J. Mullin, B. R. Keith et al., "Antitumor activity of GW572016: a dual tyrosine kinase inhibitor blocks EGF activation of EGFR/erbB2 and downstream Erk1/2 and AKT pathways," Oncogene, vol. 21, no. 41, pp. 6255-6263, 2002.

[108] D. W. Rusnak, K. Lackey, K. Affleck et al., "The effects of the novel, reversible epidermal growth factor receptor/ErbB-2 tyrosine kinase inhibitor, GW2016, on the growth of human normal and tumor-derived cell lines in vitro and in vivo," Molecular Cancer Therapeutics, vol. 1, no. 2, pp. 85-94, 2001.

[109] N. L. Spector, W. Xia, H. Burris III et al., "Study of the biologic effects of lapatinib, a reversible inhibitor of ErbB1 and ErbB2 tyrosine kinases, on tumor growth and survival pathways in patients with advanced malignancies," Journal of Clinical Oncology, vol. 23, no. 11, pp. 2502-2512, 2005.

[110] Q. Ryan, A. Ibrahim, M. H. Cohen et al., "FDA drug approval summary: lapatinib in combination with capecitabine for previously treated metastatic breast cancer that overexpresses HER-2," Oncologist, vol. 13, no. 10, pp. 1114-1119, 2008.

[111] C. E. Geyer, J. Forster, D. Lindquist et al., "Lapatinib plus capecitabine for HER2-positive advanced breast cancer," The New England Journal of Medicine, vol. 355, no. 26, pp. 2733-2743, 2006.

[112] D. Cameron, M. Casey, M. Press et al., "A phase III randomized comparison of lapatinib plus capecitabine versus capecitabine alone in women with advanced breast cancer that has progressed on trastuzumab: updated efficacy and biomarker analyses," Breast Cancer Research and Treatment, vol. 112, no. 3, pp. 533-543, 2008.

[113] J. Albanell, J. Codony, A. Rovira, B. Mellado, and P. Gascón, "Mechanism of action of anti-HER2 monoclonal antibodies: scientific update on trastuzumab and 2C4," Advances in
Experimental Medicine and Biology, vol. 532, pp. 253-268, 2003.

[114] P. Kiewe, S. Hasmüller, S. Kahlert et al., "Phase I trial of the trifunctional anti-HER $2 \times$ anti-CD3 antibody ertumaxomab in metastatic breast cancer," Clinical Cancer Research, vol. 12, no. 10, pp. 3085-3091, 2006.

[115] R. Repp, H. H. van Ojik, T. Valerius et al., "Phase I clinical trial of the bispecific antibody MDX-H210 (anti-Fc $\gamma$ RI x anti-HER-2/neu) in combination with Filgrastim (G-CSF) for treatment of advanced breast cancer," British Journal of Cancer, vol. 89, no. 12, pp. 2234-2243, 2003.

[116] H. Borghaei, R. K. Alpaugh, P. Bernardo et al., "Induction of adaptive anti-HER2/neu immune responses in a phase $1 \mathrm{~B} / 2$ trial of $2 \mathrm{~B} 1$ bispecific murine monoclonal antibody in metastatic breast cancer (E3194): a trial coordinated by the Eastern Cooperative Oncology Group," Journal of Immunotherapy, vol. 30, no. 4, pp. 455-467, 2007.

[117] L. Harris, H. Fritsche, R. Mennel et al., "American society of clinical oncology 2007 update of recommendations for the use of tumor markers in breast cancer," Journal of Clinical Oncology, vol. 25, no. 33, pp. 5287-5312, 2007.

[118] M. F. Press, G. Hung, W. Godolphin, and D. J. Slamon, "Sensitivity of HER-2/neu antibodies in archival tissue samples: potential source of error in immunohistochemical studies of oncogene expression," Cancer Research, vol. 54, no. 10, pp. 2771-2777, 1994.

[119] G. Pauletti, W. Godolphin, M. F. Press, and D. J. Slamon, "Detection and quantitation of HER-2/neu gene amplification in human breast cancer archival material using fluorescence in situ hybridization," Oncogene, vol. 13, no. 1, pp. 63-72, 1996.

[120] M. D. Pegram, G. Pauletti, and D. J. Slamon, "HER-2/neu as a predictive marker of response to breast cancer therapy," Breast Cancer Research and Treatment, vol. 52, no. 1-3, pp. 65-77, 1998.

[121] W. Hanna, H. J. Kahn, and M. Trudeau, "Evaluation of HER-2/neu (erbB-2) status in breast cancer: from bench to bedside," Modern Pathology, vol. 12, no. 8, pp. 827-834, 1999.

[122] D. J. Slamon, W. Godolphin, L. A. Jones et al., "Studies of the HER-2/neu proto-oncogene in human breast and ovarian cancer," Science, vol. 244, no. 4905, pp. 707-712, 1989.

[123] S. Bose, M. L. Lesser, L. Norton, and P. P. Rosen, "Immunophenotype of intraductal carcinoma," Archives of Pathology and Laboratory Medicine, vol. 120, no. 1, pp. 81-85, 1996.

[124] A. Moreno, B. Lloveras, A. Figueras et al., "Ductal carcinoma in situ of the breast: correlation between histologic classifications and biologic markers," Modern Pathology, vol. 10, no. 11, pp. 1088-1092, 1997.

[125] L. Mack, N. Kerkvliet, G. Doig, and F. P. O'Malley, "Relationship of a new histological categorization of ductal carcinoma in situ of the breast with size and the immunohistochemical expression of p53, c-erb B2, bcl-2, and ki-67," Human Pathology, vol. 28, no. 8, pp. 974-979, 1997.

[126] P. Meijnen, J. L. Peterse, N. Antonini, E. J. T. H. Rutgers, and M. J. van de Vijver, "Immunohistochemical categorisation of ductal carcinoma in situ of the breast," British Journal of Cancer, vol. 98, no. 1, pp. 137-142, 2008.

[127] F. Penault-Llorca, J. Adelaide, G. Houvenaeghel, J. Hassoun, D. Birnbaum, and J. Jacquemier, "Optimization of immunohistochemical detection of ERBB 2 in human breast cancer: 
impact of fixation," Journal of Pathology, vol. 173, no. 1, pp. 65-75, 1994.

[128] E. W. Kay, C. J. B. Walsh, M. Cassidy, B. Curran, and M. Leader, "C-erbB-2 immunostaining: problems with interpretation," Journal of Clinical Pathology, vol. 47, no. 9, pp. 816-822, 1994.

[129] T. W. Jacobs, A. M. Gown, H. Yaziji, M. J. Barnes, and S. J. Schnitt, "HER-2/neu protein expression in breast cancer evaluated by immunohistochemistry: a study of interlaboratory agreement," American Journal of Clinical Pathology, vol. 113, no. 2, pp. 251-258, 2000.

[130] M. Werner, A. Chott, A. Fabiano, and H. Battifora, "Effect of formalin tissue fixation and processing on immunohistochemistry," American Journal of Surgical Pathology, vol. 24, no. 7, pp. 1016-1019, 2000.

[131] I. Busmanis, F. Feleppa, A. Jones et al., "Analysis of cerbB2 expression using a panel of 6 commercially available antibodies," Pathology, vol. 26, no. 3, pp. 261-267, 1994.

[132] P. C. Roche and J. N. Ingle, "Increased HER2 with U.S. Food and drug administration-approved antibody," Journal of Clinical Oncology, vol. 17, no. 1, p. 434, 1999.

[133] K. Vani, S. R. Sompuram, P. Fitzgibbons, and S. A. Bogen, "National HER2 proficiency test results using standardized quantitative controls: characterization of laboratory failures," Archives of Pathology and Laboratory Medicine, vol. 132, no. 2, pp. 211-216, 2008.

[134] S. L. Taylor, A. Platt-Higgins, P. S. Rudland, J. H. R. Winstanley, and R. Barraclough, "Cytoplasmic staining of c-erbB-2 is not associated with the presence of detectable c-erbB-2 mRNA in breast cancer specimens," International Journal of Cancer, vol. 76, no. 4, pp. 459-463, 1998.

[135] S. L. Taylor, P. S. Rudland, and R. Barraclough, "C-erbB-2 mRNA in breast cancer specimens that exhibit membrane or cytoplasmic immunoreactivity for c-erbB-2," Oncology Research, vol. 11, no. 7, pp. 311-317, 1999.

[136] A. A. Keshgegian and A. Cnaan, "erbB-2 oncoprotein expression in breast carcinoma: poor prognosis associated with high degree of cytoplasmic positivity using CB-11 antibody," American Journal of Clinical Pathology, vol. 108, no. 4, pp. 456-463, 1997.

[137] M. P. Hoang, A. A. Sahin, N. G. Ordòñez, and N. Sneige, "HER-2/neu gene amplification compared with HER-2/neu protein overexpression and interobserver reproducibility in invasive breast carcinoma," American Journal of Clinical Pathology, vol. 113, no. 6, pp. 852-859, 2000.

[138] T. A. Thomson, M. M. Hayes, J. J. Spinelli et al., "HER-2/neu in breast cancer: interobserver variability and performance of immunohistochemistry with 4 antibodies compared with fluorescent in situ hybridization," Modern Pathology, vol. 14, no. 11, pp. 1079-1086, 2001.

[139] Dako Denmark A/S, Denmark: HercepTest package insert, http://www.dakousa.com/prod_downloadpackageinsert.pdf? objectid $=114969004$.

[140] T. W. Jacobs, A. M. Gown, H. Yaziji, M. J. Barnes, and S. J. Schnitt, "Specificity of HercepTest in determining HER2/neu status of breast cancers using the United States Food and Drug Administration-approved scoring system," Journal of Clinical Oncology, vol. 17, no. 7, pp. 1983-1987, 1999.

[141] W. C. Powell, D. G. Hicks, N. Prescott et al., "A new rabbit monoclonal antibody (4B5) for the immunohistochemical (IHC) determination of the HER2 status in breast cancer: comparison with CB11, fluorescence in situ hybridization (FISH), and interlaboratory reproducibility," Applied
Immunohistochemistry and Molecular Morphology, vol. 15, no. 1, pp. 94-102, 2007.

[142] M. F. Press, L. Bernstein, P. A. Thomas et al., "HER$2 /$ neu gene amplification characterized by fluorescence in situ hybridization: poor prognosis in node-negative breast carcinomas," Journal of Clinical Oncology, vol. 15, no. 8, pp. 2894-2904, 1997.

[143] D. Gancberg, A. Di Leo, G. Rouas et al., "Reliability of the tissue microarray based FISH for evaluation of the HER-2 oncogene in breast carcinoma," Journal of Clinical Pathology, vol. 55, no. 4, pp. 315-317, 2002.

[144] R. Bhargava, P. Lal, and B. Chen, "Feasibility of using tissue microarrays for the assessment of HER-2 gene amplification by fluorescence in situ hybridization in breast carcinoma," Diagnostic Molecular Pathology, vol. 13, no. 4, pp. 213-216, 2004.

[145] R. R. Tubbs, J. D. Pettay, E. Swain et al., "Automation of manual components and image quantification of direct dual label fluorescence in situ hybridization (FISH) for HER2 gene amplification: a feasibility study," Applied Immunohistochemistry and Molecular Morphology, vol. 14, no. 4, pp. 436-440, 2006.

[146] T. W. Jacobs, A. M. Gown, H. Yaziji, M. J. Barnes, and S. J. Schnitt, "Comparison of fluorescence in situ hybridization and immunohistochemistry for the evaluation of HER-2/neu in breast cancer," Journal of Clinical Oncology, vol. 17, no. 7, pp. 1974-1982, 1999.

[147] R. E. Jimenez, T. Wallis, P. Tabasczka, and D. W. Visscher, "Determination of Her-2/neu status in breast carcinoma: comparative analysis of immunohistochemistry and fluorescent in situ hybridization," Modern Pathology, vol. 13, no. 1, pp. 37-45, 2000.

[148] S. Wang, M. H. Saboorian, E. Frenkel, L. Hynan, S. T. Gokaslan, and R. Ashfaq, "Laboratory assessment of the status of Her-2/neu protein and oncogene in breast cancer specimens: comparison of immunohistochemistry assay with fluorescence in situ hybridisation assays," Journal of Clinical Pathology, vol. 53, no. 5, pp. 374-381, 2000.

[149] R. L. Ridolfi, M. R. Jamehdor, and J. M. Arber, "HER-2/neu testing in breast carcinoma: a combined immunohistochemical and fluorescence in situ hybridization approach," Modern Pathology, vol. 13, no. 8, pp. 866-873, 2000.

[150] S. Kakar, N. Puangsuvan, J. M. Stevens et al., "HER-2/neu assessment in breast cancer by immunohistochemistry and fluorescence in situ hybridization: comparison of results and correlation with survival," Molecular Diagnosis, vol. 5, no. 3, pp. 199-207, 2000.

[151] A. Lebeau, D. Deimling, C. Kaltz et al., "HER-2/neu analysis in archival tissue samples of human breast cancer: comparison of immunohistochemistry and fluorescence in situ hybridization," Journal of Clinical Oncology, vol. 19, no. 2, pp. 354-363, 2001.

[152] S. R. McCormick, T. J. Lillemoe, J. Beneke, J. Schrauth, and J. Reinartz, "HER2 assessment by immunohistochemical analysis and fluorescence in situ hybridization: comparison of hercep test and path vysion commercial assays," American Journal of Clinical Pathology, vol. 117, no. 6, pp. 935-943, 2002.

[153] M. A. Owens, B. C. Horten, and M. M. Da Silva, "HER2 amplification ratios by fluorescence in situ hybridization and correlation with immunohistochemistry in a cohort of 6556 breast cancer tissues," Clinical Breast Cancer, vol. 5, no. 1, pp. 63-69, 2004. 
[154] N. Dybdal, G. Leiberman, S. Anderson et al., "Determination of HER2 gene amplification by fluorescence in situ hybridization and concordance with the clinical trials immunohistochemical assay in women with metastatic breast cancer evaluated for treatment with trastuzumab," Breast Cancer Research and Treatment, vol. 93, no. 1, pp. 3-11, 2005.

[155] P. Lal, P. A. Salazar, C. A. Hudis, M. Ladanyi, and B. Chen, "HER-2 testing in breast cancer using immunohistochemical analysis and fluorescence in situ hybridization: a singleinstitution experience of 2,279 cases and comparison of dualcolor and single-color scoring," American Journal of Clinical Pathology, vol. 121, no. 5, pp. 631-636, 2004.

[156] M. Dowsett, J. Bartlett, I. O. Ellis et al., "Correlation between immunohistochemistry (Hercep Test) and fluorescence in situ hybridization (FISH) for HER-2 in 426 breast carcinomas from 37 centres," Journal of Pathology, vol. 199, no. 4, pp. 418-423, 2003.

[157] R. R. Tubbs, J. D. Pettay, P. C. Roche, M. H. Stoler, R. B. Jenkins, and T. M. Grogan, "Discrepancies in clinical laboratory testing of eligibility for trastuzumab therapy: apparent immunohistochemical false-positives do not get the message," Journal of Clinical Oncology, vol. 19, no. 10, pp. 2714-2721, 2001.

[158] E. Rossi, A. Ubiali, M. Cadei et al., "HER-2/neu in breast cancer: a comparative study between histology, immunohistochemistry, and molecular technique (FISH)," Applied Immunohistochemistry and Molecular Morphology, vol. 14, no. 2, pp. 127-131, 2006.

[159] R. D. Mass, M. F. Press, S. Anderson et al., "Evaluation of clinical outcomes according to HER2 detection by fluorescence in situ hybridization in women with metastatic breast cancer treated with trastuzumab," Clinical Breast Cancer, vol. 6, no. 3, pp. 240-246, 2005.

[160] M. F. Press, G. Sauter, L. Bernstein et al., "Diagnostic evaluation of HER-2 as a molecular target: an assessment of accuracy and reproducibility of laboratory testing in large, prospective, randomized clinical trials," Clinical Cancer Research, vol. 11, no. 18, pp. 6598-6607, 2005.

[161] E. B. Elkin, M. C. Weinstein, E. P. Winer, K. M. Kuntz, S. J. Schnitt, and J. C. Weeks, "HER-2 testing and trastuzumab therapy for metastatic breast cancer: a cost-effectiveness analysis," Journal of Clinical Oncology, vol. 22, no. 5, pp. 854-863, 2004.

[162] M. F. Press, G. Scatter, J. Lee, J. M. S. Bartlett, and D. J. Slamon, "Guidelines for human epidermal growth factor receptor 2 testing: biologic and methodologic considerations," Journal of Clinical Oncology, vol. 27, no. 8, pp. 1323-1333, 2009.

[163] L. Hammock, M. Lewis, C. Phillips, and C. Cohen, "Strong HER-2/neu protein overexpression by immunohistochemistry often does not predict oncogene amplification by fluorescence in situ hybridization," Human Pathology, vol. 34, no. 10, pp. 1043-1047, 2003.

[164] M. Cuadros and R. Villegas, "Systematic review of HER2 breast cancer testing," Applied Immunohistochemistry and Molecular Morphology, vol. 17, no. 1, pp. 1-7, 2009.

[165] H. Yaziji, L. C. Goldstein, T. S. Barry et al., "HER-2 testing in breast cancer using parallel tissue-based methods," Journal of the American Medical Association, vol. 291, no. 16, pp. 1972-1977, 2004.

[166] P. Lal, P. A. Salazar, M. Ladanyi, and B. Chen, "Impact of polysomy 17 on Her-2/neu immunohistochemistry in breast carcinomas without Her-2/neu gene amplification," Journal of Molecular Diagnostics, vol. 5, no. 3, pp. 155-159, 2003.

[167] D. Varshney, Y. Y. Zhou, S. A. Geller, and R. Alsabeh, "Determination of HER-2 status and chromosome 17 polysomy in breast carcinomas comparing HercepTest and PathVysion FISH assay," American Journal of Clinical Pathology, vol. 121, no. 1, pp. 70-77, 2004.

[168] E. Downs-Kelly, B. J. Yoder, M. Stoler et al., "The influence of polysomy 17 on HER2 gene and protein expression in adenocarcinoma of the breast: a fluorescent in situ hybridization, immunohistochemical, and isotopic mRNA in situ hybridization study," American Journal of Surgical Pathology, vol. 29, no. 9, pp. 1221-1227, 2005.

[169] C. L. Hyun, H. E. Lee, K. S. Kim et al., "The effect of chromosome 17 polysomy on HER-2/neu status in breast cancer," Journal of Clinical Pathology, vol. 61, no. 3, pp. 317-321, 2008.

[170] R. Torrisi, N. Rotmensz, V. Bagnardi et al., "HER2 status in early breast cancer: relevance of cell staining patterns, gene amplification and polysomy 17," European Journal of Cancer, vol. 43, no. 16, pp. 2339-2344, 2007.

[171] S. S. Shah, Y. Wang, J. Tull, and S. Zhang, "Effect of high copy number of HER2 associated with polysomy 17 on HER2 protein expression in invasive breast carcinoma," Diagnostic Molecular Pathology, vol. 18, no. 1, pp. 30-33, 2009.

[172] S. Wang, M. H. Saboorian, E. P. Frenkel et al., "Aneusomy 17 in breast cancer: its role in HER-2/neu protein expression and implication for clinical assessment of HER-2/neu status," Modern Pathology, vol. 15, no. 2, pp. 137-145, 2002.

[173] U. Krishnamurti, J. L. Hammers, F. D. Atem, P. D. Storto, and J. F. Silverman, "Poor prognostic significance of unamplified chromosome 17 polysomy in invasive breast carcinoma," Modern Pathology, vol. 22, no. 8, pp. 1044-1048, 2009.

[174] I. Vanden Bempt, P. Van Loo, M. Drijkoningen et al., "Polysomy 17 in breast cancer: clinicopathologic significance and impact on HER-2 testing," Journal of Clinical Oncology, vol. 26, no. 30, pp. 4869-4874, 2008.

[175] M. Hofmann, O. Stoss, T. Gaiser et al., "Central HER2 IHC and FISH analysis in a trastuzumab (Herceptin) phase II monotherapy study: assessment of test sensitivity and impact of chromosome 17 polysomy," Journal of Clinical Pathology, vol. 61, no. 1, pp. 89-94, 2008.

[176] L. Downey, R. B. Livingston, M. Koehler et al., "Chromosome 17 polysomy without human epidermal growth factor receptor 2 amplification does not predict response to lapatinib plus paclitaxel compared with paclitaxel in metastatic breast cancer," Clinical Cancer Research, vol. 16, no. 4, pp. 1281-1288, 2010.

[177] I.-T. Yeh, M. A. Martin, R. S. Robetorye et al., "Clinical validation of an array CGH test for HER2 status in breast cancer reveals that polysomy 17 is a rare event," Modern Pathology, vol. 22, no. 9, pp. 1169-1175, 2009.

[178] J. T. Lewis, R. P. Ketterling, K. C. Halling, C. Reynolds, R. B. Jenkins, and D. W. Visscher, "Analysis of intratumoral heterogeneity and amplification status in breast carcinomas with equivocal (2+) HER-2 immunostaining," American Journal of Clinical Pathology, vol. 124, no. 2, pp. 273-281, 2005.

[179] R. R. Tubbs, D. G. Hicks, J. Cook et al., "Fluorescence in situ hybridization (FISH) as primary methodology for the assessment of HER2 status in adenocarcinoma of the breast: a single institution experience," Diagnostic Molecular Pathology, vol. 16, no. 4, pp. 207-210, 2007. 
[180] J. M. Wu, M. K. Halushka, and P. Argani, "Intratumoral heterogeneity of HER-2 gene amplification and protein overexpression in breast cancer," Human Pathology, vol. 41, no. 6, pp. 914-917, 2010.

[181] A. Nassar, A. Radhakrishnan, I. A. Cabrero, G. A. Cotsonis, and C. Cohen, "Intratumoral heterogeneity of immunohistochemical marker expression in breast carcinoma: a tissue microarray-based study," Applied Immunohistochemistry and Molecular Morphology, vol. 18, no. 5, pp. 433-441, 2010.

[182] H. Fujii, C. Marsh, P. Cairns, D. Sidransky, and E. Gabrielson, "Genetic divergence in the clonal evolution of breast cancer," Cancer Research, vol. 56, no. 7, pp. 1493-1497, 1996.

[183] Y. Sekido, S. Umemura, S. Takekoshi et al., "Heterogeneous gene alterations in primary breast cancer contribute to discordance between primary and asynchronous metastatic/recurrent sites: HER2 gene amplification and p53 mutation," International Journal of Oncology, vol. 22, no. 6, pp. 1225-1232, 2003.

[184] F. Cardoso, A. Di Leo, D. Larsimont et al., "Evaluation of HER2, p53, bcl-2, topoisomerase II- $\alpha$, heat shock proteins 27 and 70 in primary breast cancer and metastatic ipsilateral axillary lymph nodes," Annals of Oncology, vol. 12, no. 5, pp. 615-620, 2001.

[185] R. M. Quddus, J. C. Sung, C. Zhang, T. Pasqueriello, M. Eklund, and M. M. Steinhoff, "HER-2/neu expression in locally advanced breast carcinomas: pre-and postneoadjuvant chemotherapy," Breast Cancer, vol. 12, no. 4, pp. 294-298, 2005.

[186] T. D’Alfonso, Y.-F. Liu, S. Monni, P. P. Rosen, and S. J. Shin, "Accurately assessing HER-2/neu status in needle core biopsies of breast cancer patients in the Era of neoadjuvant therapy: emerging questions and considerations addressed," American Journal of Surgical Pathology, vol. 34, no. 4, pp. 575-581, 2010.

[187] G. H. Vance, T. S. Barry, K. J. Bloom et al., "Genetic heterogeneity in HER2 testing in breast cancer panel summary and guidelines," Archives of Pathology and Laboratory Medicine, vol. 133, no. 4, pp. 611-612, 2009.

[188] Invitrogen package insert, http://tools.invitrogen.com/content/sfs/manuals/PI840150\%20CISH\%20Package\%20Insert \%20Rev\%200.0.pdf.

[189] M. Tanner, D. Gancberg, B. A. D. Leo et al., "Chromogenic in situ hybridization: a practical alternative for fluorescence in situ hybridization to detect HER-2/neu oncogene amplification in archival breast cancer samples," American Journal of Pathology, vol. 157, no. 5, pp. 1467-1472, 2000.

[190] N. Dandachi, O. Dietze, and C. Hauser-Kronberger, "Chromogenic in situ hybridization: a novel approach to a practical and sensitive method for the detection of HER2 oncogene in archival human breast carcinoma," Laboratory Investigation, vol. 82, no. 8, pp. 1007-1014, 2002.

[191] L. Arnould, Y. Denoux, G. MacGrogan et al., "Agreement between chromogenic in situ hybridisation (CISH) and FISH in the determination of HER2 status in breast cancer," British Journal of Cancer, vol. 88, no. 10, pp. 1587-1591, 2003.

[192] J. Isola, M. Tanner, A. Forsyth, T. G. Cooke, A. D. Watters, and J. M. S. Bartlett, "Interlaboratory comparison of HER2 oncogene amplification as detected by chromogenic and fluorescence in situ hybridization," Clinical Cancer Research, vol. 10, no. 14, pp. 4793-4798, 2004.

[193] R. Bhargava, P. Lal, and B. Chen, "Chromogenic in situ hybridization for the detection of HER-2/neu gene amplification in breast cancer with an emphasis on tumors with borderline and low-level amplification: does it measure up to fluorescence in situ hybridization?" American Journal of Clinical Pathology, vol. 123, no. 2, pp. 237-243, 2005.

[194] Y. Gong, M. Gilcrease, and N. Sneige, "Reliability of chromogenic in situ hybridization for detecting HER-2 gene status in breast cancer: comparison with fluorescence in situ hybridization and assessment of interobserver reproducibility," Modern Pathology, vol. 18, no. 8, pp. 1015-1021, 2005.

[195] Y. Gong, W. Sweet, Y.-J. Duh et al., "Chromogenic in situ hybridization is a reliable method for detecting her2 gene status in breast cancer a multicenter study using conventional scoring criteria and the new asco/cap recommendations," American Journal of Clinical Pathology, vol. 131, no. 4, pp. 490-497, 2009.

[196] F. Penault-Llorca, M. Bilous, M. Dowsett et al., "Emerging technologies for assessing HER2 amplification," American Journal of Clinical Pathology, vol. 132, no. 4, pp. 539-548, 2009.

[197] B. G. Papouchado, J. Myles, R. V. Lloyd et al., "Silver in situ hybridization (SISH) for determination of HER2 gene status in breast carcinoma: comparison with fish and assessment of interobserver reproducibility," American Journal of Surgical Pathology, vol. 34, no. 6, pp. 767-776, 2010.

[198] M. Dietel, I. O. Ellis, H. Höfler et al., "Comparison of automated silver enhanced in situ hybridisation (SISH) and fluorescence ISH (FISH) for the validation of HER2 gene status in breast carcinoma according to the guidelines of the American Society of Clinical Oncology and the College of American Pathologists," Virchows Archiv, vol. 451, no. 1, pp. 19-25, 2007.

[199] A. Carbone, G. Botti, A. Gloghini et al., "Delineation of HER2 gene status in breast carcinoma by silver in situ hybridization is reproducible among laboratories and pathologists," Journal of Molecular Diagnostics, vol. 10, no. 6, pp. 527-536, 2008.

[200] F. R. Fritzsche, P. K. Bode, H. Moch, G. Kristiansen, Z. Varga, and B. Bode, "Determination of the her-2/neu gene amplification status in cytologic breast cancer specimens using automated silver-enhanced in-situ hybridization (SISH)," American Journal of Surgical Pathology, vol. 34, no. 8, pp. 1180-1185, 2010.

[201] R. Tubbs, J. Pettay, M. Skacel et al., "Gold-facilitated in situ hybridization: a bright-field autometallographic alternative to fluorescence in situ hybridization for detection of HER2/neu gene amplification," American Journal of Pathology, vol. 160, no. 5, pp. 1589-1595, 2002.

[202] E. Downs-Kelly, J. Pettay, D. Hicks et al., "Analytical validation and interobserver reproducibility of EnzMet GenePro: a second-generation bright-field metallography assay for concomitant detection of HER2 gene status and protein expression in invasive carcinoma of the breast," American Journal of Surgical Pathology, vol. 29, no. 11, pp. 1505-1511, 2005.

[203] H. Nitta, B. Hauss-Wegrzyniak, M. Lehrkamp et al., "Development of automated brightfield double in Situ hybridization (BDISH) application for HER2 gene and chromosome 17 centromere (CEN 17) for breast carcinomas and an assay performance comparison to manual dual color HER2 fluorescence in Situ hybridization (FISH)," Diagnostic Pathology, vol. 3, no. 1, article 41, 2008.

[204] A. C. Wolff, M. E. H. Hammond, J. N. Schwartz et al., "American Society of Clinical Oncology/College of American 
Pathologists guideline recommendations for human epidermal growth factor receptor 2 testing in breast cancer," Journal of Clinical Oncology, vol. 25, no. 1, pp. 118-145, 2007.

[205] A. M. Dastane, R. Alsabeh, and S. Bose, "Effect of ASCO/CAP recommended guideline for positive Her2/neu stain on FISH concordance-an evidence based study," Modern Pathology $A$, vol. 28, article 21, 2008.

[206] L. P. Middleton, K. M. Price, P. Puig et al., "Implementation of american society of clinical oncology/college of american pathologists HER2 guideline recommendations in a tertiary care facility increases HER2 immunohistochemistry and fluorescence in situ hybridization concordance and decreases the number of inconclusive cases," Archives of Pathology and Laboratory Medicine, vol. 133, no. 5, pp. 775-780, 2009.

[207] Y.-H. Liu, F.-P. Xu, J.-Y. Rao et al., "Justification of the change from $10 \%$ to $30 \%$ for the immunohistochemical HER2 scoring criterion in breast cancer," American Journal of Clinical Pathology, vol. 132, no. 1, pp. 74-79, 2009.

[208] O. Hameed, A. L. Adams, A. C. Baker et al., "Using a higher cutoff for the percentage of HER2+ cells decreases interobserver variability in the interpretation of HER2 immunohistochemical analysis," American Journal of Clinical Pathology, vol. 130, no. 3, pp. 425-427, 2008.

[209] H. L. Gilmore, L. C. Collins, J. L. Connolly, and S. J. Schnitt, "Impact of the new American Society of Clinical Oncology (ASCO)/College of American Pathologists (CAP) guidelines on the determination of breast cancer HER2 status," Modern Pathology A, vol. 32, article 21, 2008.

[210] S. S. Shah, R. P. Ketterling, M. P. Goetz et al., "Impact of American Society of Clinical Oncology/College of American Pathologists guideline recommendations on HER2 interpretation in breast cancer," Human Pathology, vol. 41, no. 1, pp. 103-106, 2010.

[211] E. A. Perez, E. H. Romond, V. J. Suman et al., "Updated results of the combined analysis of NCCTG N9831 and NSABP B-31 adjuvant chemotherapy with/without trastuzumab in patients with HER2-positive breast cancer," Journal of Clinical Oncology, vol. 25, no. 18, supplement, p. 512, 2007.

[212] S. Paik, C. Kim, and N. Wolmark, "HER2 status and benefit from adjuvant trastuzumab in breast cancer," The New England Journal of Medicine, vol. 358, no. 13, pp. 1409-1411, 2008.

[213] E. Perez, M. Reinholz, A. Dueck et al., "Do the ASCO/CAP 2007 HER2 testing guidelines improve prediction of benefit to adjuvant trastuzumab? Data from North Central Cancer Treatment Group N9831 adjuvant trial," Cancer Research, vol. 69, no. 24, supplement, p. 524s, 2009. 


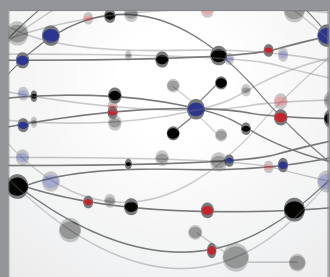

The Scientific World Journal
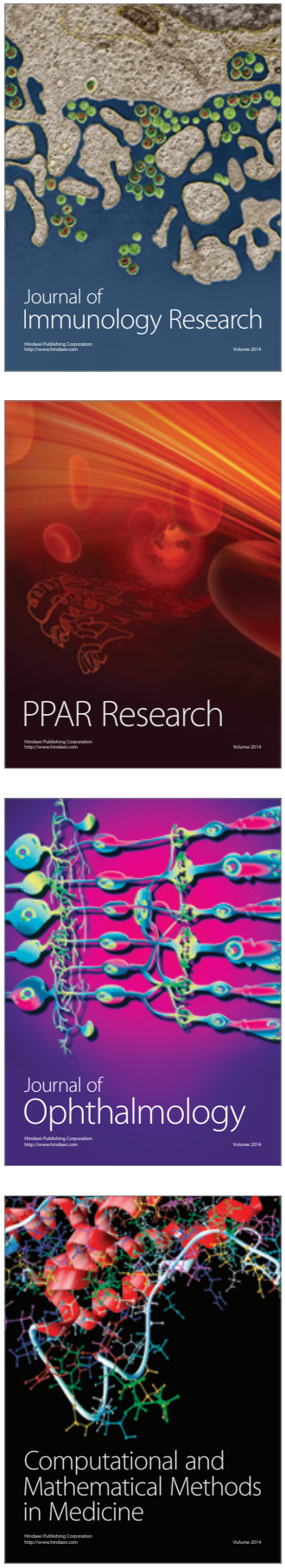

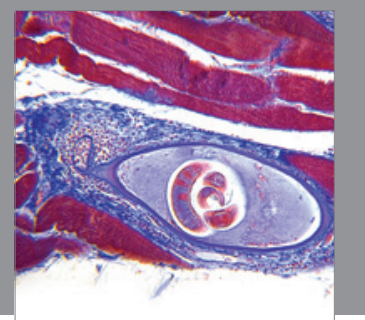

Gastroenterology

Research and Practice
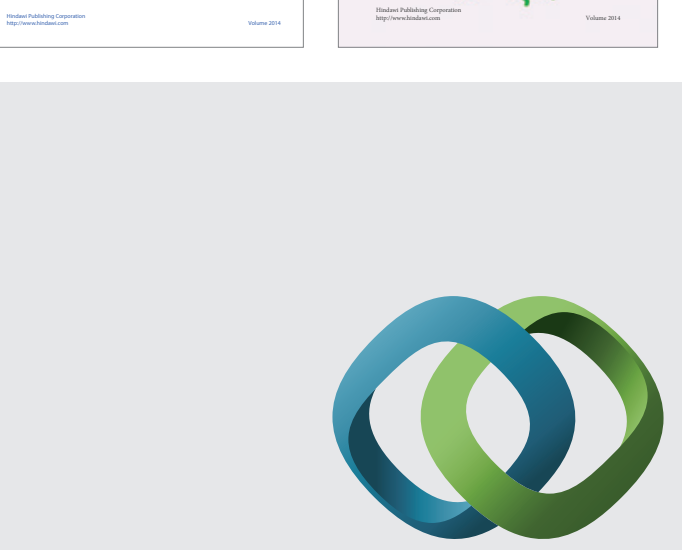

\section{Hindawi}

Submit your manuscripts at

http://www.hindawi.com
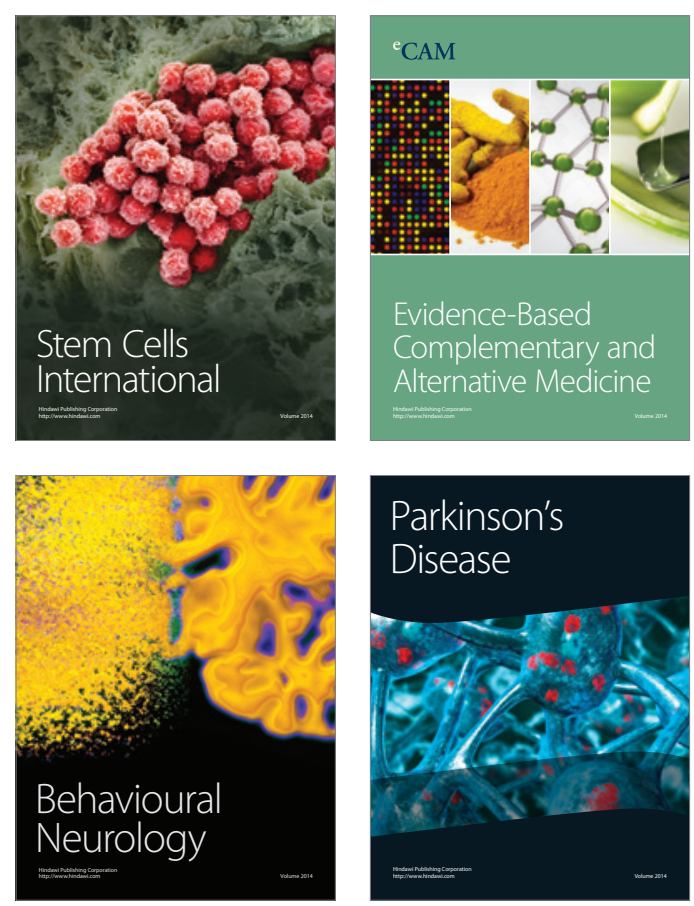

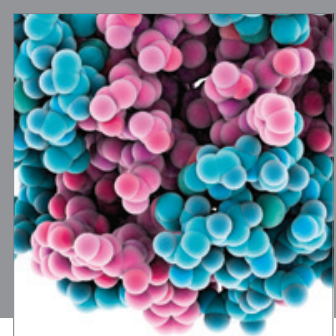

Journal of
Diabetes Research

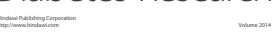

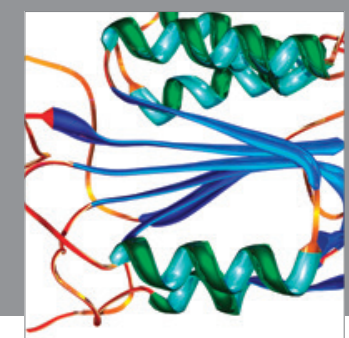

Disease Markers
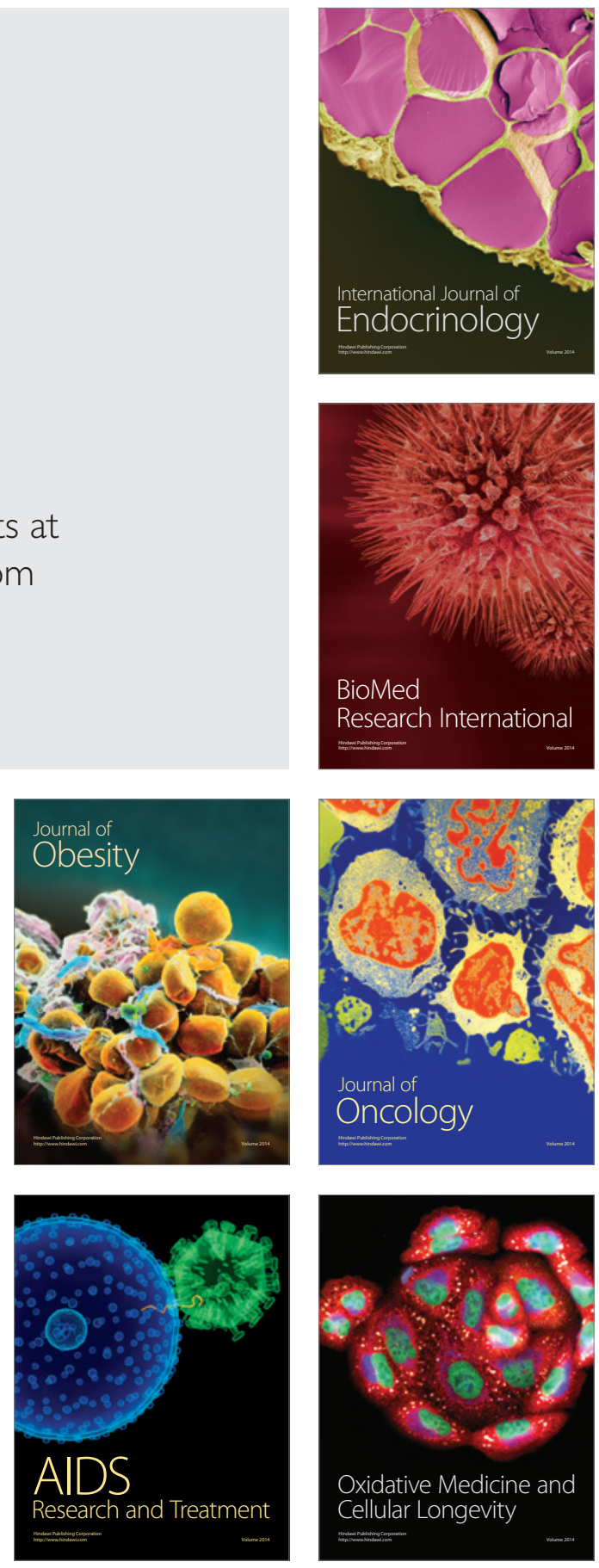